\title{
Synthetic Analogs of Streptococcus pneumoniae Capsular Polysaccharides and Immunogenic Activities of Glycoconjugates
}

\author{
M. L. Gening ${ }^{a}$, E A. Kurbatova ${ }^{b}$, and N. E. Nifantiev ${ }^{a}, 1$ \\ ${ }^{a}$ Zelinsky Institute of Organic Chemistry, Russian Academy of Sciences, Moscow, 119991 Russia \\ ${ }^{b}$ Mechnikov Research Institute for Vaccines and Sera, Moscow, 105064 Russia \\ Received July 30, 2020; revised August 14, 2020; accepted August 15, 2020
}

\begin{abstract}
Streptococcus pneumoniae is a Gram-positive bacterium (pneumococcus) that causes severe diseases in adults and children. It was established that some capsular polysaccharides of the clinically significant serotypes of $S$. pneumoniae in the composition of commercial pneumococcal polysaccharide or conjugate vaccines exhibit low immunogenicity. The review considers production methods and structural features of the synthetic oligosaccharides from the problematic pneumococcal serotypes that are characterized with low immunogenicity due to destruction or detrimental modification occurring in the process of their preparation and purification. Bacterial serotypes that cause severe pneumococcal diseases as well as serotypes not included in the composition of the pneumococcal conjugate vaccines are also discussed. It is demonstrated that the synthetic oligosaccharides corresponding to protective glycotopes of the capsular polysaccharides of various pneumococcal serotypes are capable of inducing formation of the protective opsonizing antibodies and immunological memory. Optimal constructs of oligosaccharides from the epidemiologically significant pneumococcal serotypes are presented that can be used for designing synthetic pneumococcal vaccines, as well as test systems for diagnosis of $S$. pneumoniae infections and monitoring of vaccination efficiency .
\end{abstract}

Keywords: pneumococci, vaccine, oligosaccharide, ligand, immunogen, antibodies, opsonophagocytosis, protective activity

DOI: $10.1134 / \mathrm{S} 1068162021010076$

\section{INTRODUCTION}

The Gram-positive bacteria Streptococcus pneumoniae (pneumococcus) cause severe invasive and noninvasive diseases in children and adults and also can persist in the nasopharyngeal mucosa of healthy carriers without causing clinical manifestations of the infection. Most pneumococcal strains are surrounded by a polysaccharide capsule. More than 90 pneumococcal serotypes have been identified based on the structurally different capsular polysaccharides (CP) expressed by $S$. pneumoniae [1-3].

Pneumococcal infections can be divided into invasive and noninvasive types based on the severity of the disease. Bacteremia, meningitis, pneumonia, and other pathological conditions in which the pathogen is

Abbreviations: BSA, bovine serum albumin; CD, cluster of differentiation antigens; CRM197, nontoxic form of recombinant diphtheria anatoxin (protein carrier); D-AAT, 2-acetamido-4amino-2,4,6-trideoxy-D-galactose; GM-CSF, granulocytemacrophage colony-stimulating factor; IFN $\gamma$, interferon gamma; IL, interleukin; KLH, keyhole limpet hemocyanin; $\mathrm{mAb}$, monoclonal antibodies; MALDI-TOF, matrix-assisted laser desorption/ionization time-of-flight; NK, natural killers; TLR, Toll-like receptor; TNF $\alpha$, tumor necrosis factor alpha; $\mathrm{CP}$, capsular polysaccharide.

${ }^{1}$ Corresponding author: phone: +7 (499) 135-87-84; e-mail: nen@ioc.ac.ru. isolated from usually sterile organs and tissues (blood, cerebrospinal fluid, less often synovial, pleural, and pericardial fluids) are commonly considered as invasive infections. Infections of the upper respiratory tract (otitis media, paranasal sinusitis) and the lower respiratory tract (bronchitis), as well as other relatively rarely diagnosed infections (conjunctivitis, peritonitis, arthritis, polyarthritis, etc.) belong to the noninvasive forms of the disease. The invasive pneumococcal diseases can be fatal, especially in young children, elderly, and immunocompromised individuals $[4,5]$. Severity of the course of pneumococcal infection depends on the serotype of $S$. pneumoniae [6-11]. In particular, the $S$. pneumoniae serotypes 3, 6B, 19A, 19F, and 23F that have a well-developed capsule belong to the serotypes with low invasiveness and cause diseases associated with high risk of death, primarily in immunocompromised individuals. The serotypes $1,7 \mathrm{~F}, 4,9 \mathrm{~N}$, $9 \mathrm{~V}$, and 14 with medium-to-high invasive potential and thin capsule most often cause disease in healthy individuals, acting as primary pathogens $[12,13]$.

\section{Epidemiology of S. pneumoniae}

Prevalence of the pneumococcal serotypes depends on localization of the site of infection, geo- 
graphic location, and age of the patient [6]. Pneumococcal serotypes vary significantly in virulence $[6,7$, 14-17]. According to the WHO, in $2007 \sim 80-90 \%$ of all pneumococcal diseases were caused by 20 serotypes of $S$. pneumoniae [18, 19].

The data on prevalence of various serotypes of pneumococcus in the United States, Asia, Africa, Europe, Latin America, Australia, New Zealand, Belarus, Ukraine, and Russia in different years among children and adults are available in numerous publications [20-28]. In 2012, a large-scale epidemiological study was carried out in six countries of Southeast Asia to study prevalence of various serotypes of $S$. pneumoniae. Serotypes 1, 3, 6B, 14, 19A, 19F, and 23F were isolated most often. No significant region-related differences were identified in the prevalence of one serotype or another [29].

It was shown that the serotypes 1 and 14 were predominantly isolated from the blood of patients, serotypes 6,10 , and 23 were isolated from cerebrospinal fluid, and serotypes 3,19 , and 23 were isolated from the middle ear fluid of children [8]. The serotypes 6A, $6 \mathrm{~B}, 14,19 \mathrm{~F}$, and 23 are considered as main "pediatric" strains of pneumococcus $[4,30]$. In the United States, the serotypes $14,6 \mathrm{~B}, 19 \mathrm{~F}, 18 \mathrm{C}, 23 \mathrm{~F}$, and $9 \mathrm{~V}$ caused $80 \%$ of meningitis in young children, while they accounted for only $50 \%$ of all isolates in the children over 6 years old [6, 31-34].

In Japan the serotypes 3, 4, 19F, and 23F were isolated from the adults with respiratory tract diseases from 2011 to 2013 [35]. In two other studies conducted in the same geographic region, the serotype 3 was found to be most widespread [36, 37]. The serotypes 3 , $12,15,19 \mathrm{~A}$, and $19 \mathrm{~F}$ were identified as the most common causative agents in the invasive pneumococcal diseases in 2014-2016 in the southeast of the Arabian Peninsula [38].

The strains of serotypes $3,6,11,19$, and 23 were most frequently identified in Korea and Spain [39, 40]. Another study showed that the serotypes 1, 3, 7F, and 19A were predominant in Spain in 2001-2014. $S$. pneumoniae serotype 3 was the most common one identified in patients with complications that developed during hospitalization. The serotype $22 \mathrm{~F}$ was the most frequently identified serotype not included in the Prevnar $13^{\circledR}$ (Pfizer) vaccine. A significant part of adults vaccinated against pneumococcus in childhood suffered from the community-acquired pneumonia caused by the serotypes included in the vaccines with which they had been immunized in childhood. This determines the need to develop vaccination strategy to reduce the disease incidence in adults [41]. In the United States, serotypes 3, 6, 14, 18, 19, and 23 are the most common cause of otitis media [30, 42].
Evaluation of the prevalence of various pneumococcal serotypes in Russia revealed that serotypes 3,6, $9,14,19$, and 23, and to a lesser extent serotypes 7 and 18 , are dominant in the children that are asymptomatic carriers [21]. The serotype 19 was found in acute otitis media with the highest frequency; while the serotypes $3,4,6,8,9,14,15,20,22$, and 23 were isolated less frequently. The serotypes 19 , and to a lesser extent serotypes 6,14 , and 23 , were identified in the children with community-acquired pneumonia; the serotypes 5 and 1 were isolated from lung tissues of children with invasive pneumococcal infection. The predominant serotypes causing invasive infections were 8,19 , to a much lesser extent, 1,5 , and 23 . Prevalence of the serotypes $3,6,15$, and 19 among children with pneumococcal infections was also noted in other studies [43]. The strains were susceptible to penicillin, with the exception of all strains belonging to serotype 19 [21]. This is in agreement with the data reported by other authors indicating that the modern $S$. pneumoniae strains are sensitive to penicillin, but resistant to macrolides (erythromycin) [38].

Information on the landscape of pneumococcal serotypes in Moscow is limited. Among the strains of pneumococcus obtained from the patients with pneumococcal meningitis in Moscow in 2000-2007, the serotypes 3,6 , and 19 were prevalent in all age categories. The serotypes 1, 3, 4, 6B, 6A, 7F, 15A, 15B, 18C, and $19 \mathrm{~F}$ were most frequently isolated in Moscow accounting for $63 \%$ of the identified strains. Comparison of the serotype landscape of this pathogen obtained in 1980-1999 with the strain serotypes identified in 2000-2012 showed a difference in the structure and proportion of the dominant serotypes. While the prevalent serotypes among the strains isolated in 1980-1999 (in decreasing order of significance) were $1,3,19 \mathrm{~F}, 6 \mathrm{~A}, 7 \mathrm{~F}, 12 \mathrm{~F}, 18 \mathrm{C}$, and 19A, the serotypes 3 , $19 \mathrm{~F}, 6 \mathrm{~B}, 7 \mathrm{~F}, 15 \mathrm{~A}, 15 \mathrm{~B}, 1,4$, and $6 \mathrm{~A}$ were most frequently isolated in 2000-2012 [44].

Thus, the serotypes $\mathbf{1}, 2, \mathbf{3}, 4,5, \mathbf{6 A} / \mathbf{B}, 7 \mathrm{~F}, 8,9,11$, $12,14,15 \mathrm{~A} / \mathrm{B}, 18 \mathrm{C}, 19 \mathrm{~A} / \mathrm{F}, 20,22$, and $23 \mathrm{~F}$ are of the highest clinical significance in the world today; in Russia these are serotypes $\mathbf{1}, \mathbf{3}, \mathbf{4}, \mathbf{6 A} / \mathbf{B}, \mathbf{7 F}, 12,14$, 15A/B, 18C and 19F (serotypes in bold are found with the highest frequency). It is obvious that this set of strains can change and even expand over time due to increase of epidemiological significance of other pneumococcal serotypes.

\section{Vaccination to Prevent Pneumococcal Infection}

The success of vaccination in preventing infections caused by $S$. pneumoniae largely depends on the degree to which the serotype composition of the vaccine matches the spectrum of circulating pneumococcal strains in the region of the vaccine application. In the 
controlled trial of the 13-valent pneumococcal conjugate vaccine in children, the serum levels of antibodies to all serotypes in the vaccine composition increased after immunization in all age groups. Production of antibodies induced against the CPs of serotypes 6A, $14,19 \mathrm{~F}$, and $23 \mathrm{~F}$ was weak in children under 4.5 years old [45].

Increase in the opsonophagocytic activity and concentration of the CPs-specific IgG antibodies to all pneumococcal serotypes included in the corresponding vaccine was noted in the first phase of clinical trials of the 20-valent pneumococcal conjugate vaccine containing seven new pneumococcal serotypes (8, $10 \mathrm{~A}, 11 \mathrm{~A}, 12 \mathrm{~F}, 15 \mathrm{~B}, 22 \mathrm{~F}$, and $33 \mathrm{~F}$ ) that was developed to expand the serotype coverage of the existing conjugate vaccines (Prevnar $7^{\circledR}$, Synflorix ${ }^{\circledR}(\mathrm{GSK})$, and Prevnar $\left.13^{\circledR}\right)$ [46].

Each of the CPs of $S$. pneumoniae serotypes 1, 3, 4, $5,6 \mathrm{~B}, 7 \mathrm{~F}, 9 \mathrm{~V}, 14,18 \mathrm{C}, 19 \mathrm{~F}$, and 23 in the 10 -valent pneumococcal conjugate vaccine Synflorix ${ }^{\circledR}$ is conjugated to the protein D isolated from Haemophilus influenzae. Significant increase of the IgG antibodies to CPs of serotypes included in this vaccine was observed in the clinical trials in children [47]. Vaccination helped to reduce the number of cases of infection caused by the vaccine strains but did not significantly affect incidence of the diseases caused by nonvaccine pneumococcus serotypes.

The serotypes 3 (37 cases), 6B (27 cases), 14 (23 cases), 19F (67 cases), and 23F (23 cases) caused the largest number of pneumococcal otitis media cases. A significant protective effect of vaccination was established for all serotypes, with the exception of serotype 3, which varied from $44.4 \%$ (for the serotype 19F) to $95.5 \%$ (for the serotype 14). As for serotype 3, the total number of cases of acute otitis media in the pneumococcal vaccine group and the control group was 20 and 17 , respectively [48]. Increase in the titer of antibodies against pneumococcal CPs and their opsonizing activity was noted [49]. It was shown that $\mathrm{IgG}$ antibodies with high opsonophagocytic activity are of key importance in the prevention of acute otitis media, while the antibody titer alone is not an adequate indicator of the vaccine effectiveness [50]. Shiramoto et al. showed that immunogenicity of both Prevnar $13^{\circledR}$ and Pneumovax $^{\circledR} 23$ (Merck) vaccines in elderly people, which was assessed by the titer of antibodies and their opsonophagocytic activity, was lower for the serotype $3 \mathrm{CP}$ in comparison with other pneumococcal serotypes [51]. Immunization with the pneumococcal polysaccharide vaccine did not result in the increase in the titer of antibodies against the $S$. pneumoniae serotype $3 \mathrm{CP}$ in individuals over 65 years old and in young adults, while the titer of antibodies against other studied serotypes $(1,5,6 \mathrm{~B}, 8$, and 14$)$ increased in both groups [52]. It can be concluded based on the conducted studies that immunogenicity of the CPs from different pneumococcal serotypes is not the same [53].

\section{COMPOSITION OF $S$. pneumoniae CAPCULAR POLYSACCHARIDES AND SYNTHESIS OF RELATED OLIGOSACCHARIDES FOR VACCINE DEVELOPMENT}

Pneumococcal vaccines currently approved for use are produced using either bacterial CPs of actual pneumococcal serotypes or CPs conjugated with a protein carrier followed by addition of an adjuvant. CPs are isolated from the culture medium after inactivation of the pathogen [54]. Disadvantage of the traditional vaccines based on pneumococcus CPs is the need to work with a microbial culture of virulent pneumococcal strains. Purification of CPs from bacterial impurities is very labor-intensive, and conjugation with a protein carrier required for induction of the Tdependent immune response with formation of opsonizing IgG antibodies and immunological memory is not always successful. The CP preparations isolated from culture medium contain, even after purification, a mixture of bacterial cell antigens including cell wall polysaccharides (teichoic acid or C-polysaccharide), nucleic acids, and others. Therefore, the resulting product is chemically heterogeneous, which can be detrimental for subsequent conjugation with a protein carrier [54, 55].

Bacterial CPs contain repeating oligosaccharide units of various lengths [56] consisting, for example, of two (serotype 3 ) or eight (serotype 17A) monosaccharide residues in the case of $S$. pneumoniae [57]. The antibodies induced against one of the $\mathrm{CP}$ epitopes could exert protective function, while the antibodies against another one could be not effective. In a number of cases, low efficiency of CPs could be associated with the individual features of particular CPs such as different CP conformations in the composition of bacterial capsule and in the vaccine. This, in turn, can result in the different epitope specificity of the antibodies induced by the pneumococcus itself and by the vaccine.

The $S$. pneumoniae CP epitopes can be also presented on synthetic oligosaccharides [30], which are conjugated to a protein carrier by common chemical techniques to obtain a semisynthetic vaccine. Currently, oligosaccharides have been synthesized for serotypes $1-4,6 \mathrm{~A} / \mathrm{B}, 7 \mathrm{~F}, 8,9 \mathrm{~A} / \mathrm{V}, 12,14,17 \mathrm{~F}, 18 \mathrm{C}$, $19 \mathrm{~A} / \mathrm{F}, 22 \mathrm{~F}, 23 \mathrm{~F}, 27$, and 29 [58, 59]. CP hydrolysis, chemical synthesis, and biosynthesis can be used to produce oligosaccharides containing several repeating units corresponding to the CP structure [58, 59]. Several oligosaccharides have been successfully obtained by hydrolysis. It is difficult to control chemical structure, oligosaccharide length, and presence of bacterial impurities in this process, which are the main drawbacks of this technique. Chemical synthesis of several repeating units of an oligosaccharide has become available, but it is a multistep and quite complex process. Combination of chemical synthesis and biosynthesis is an alternative approach that allows produc- 


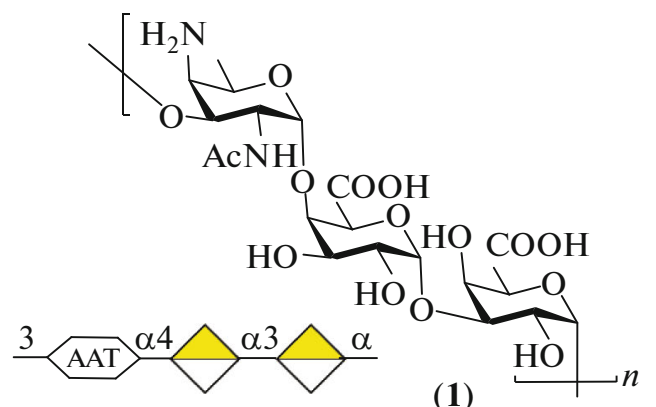

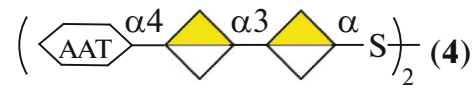

$\left(\langle\mathrm{AAT} \perp-\mathrm{S})_{2}(3)\right.$
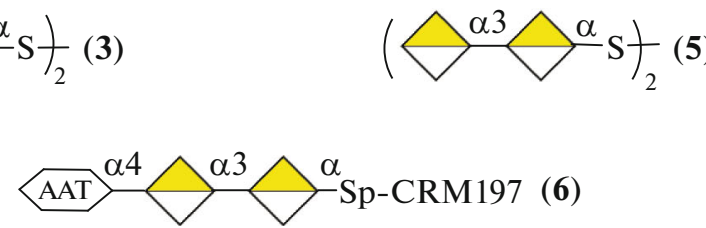

(6)

Fig. 1. The structure of the capsular polysaccharide of Streptococcus pneumoniae serotype 1 (repeating unit (1)), synthetic oligosaccharide derivatives (2-5), and conjugate with CRM197 (6). Hereinafter, to depict oligosaccharide sequences, the symbolic designations of monosaccharide residues are used.

tion of large quantities of oligosaccharides with long chain. Biosynthesis of the synthetic $\mathrm{CP}$ analogs of the serotypes 3,14, and 19F has been reported [58].

The immune response to oligosaccharides is highly specific. Interestingly, some oligosaccharides conjugated to a protein carrier induce even higher titer of antibodies against $\mathrm{CP}$ than the corresponding $\mathrm{CP}$ conjugates [60]. Identification of the immunogenic glycotopes of $S$. pneumoniae CPs that provide protective capacity to the pneumococcal glycoconjugate vaccines, could help to increase their effectiveness. The use of short oligosaccharides obtained via chemical means provides possibility to control conjugation process and to evaluate immunogenicity of the vaccines produced with varying structural parameters of the components such as length of the oligosaccharide fragment and carbohydrate/protein ratio, which is hard to do in the case of large oligosaccharides or polysaccharides [61]. Thus, the synthetic oligosaccharides represent an attractive alternative to heterogeneous preparations of purified bacterial CPs, which have been used for production of the first commercial pneumococcal vaccines [62, 63]. Immunogenic properties of glycoconjugates can be optimized by using synthetic antigen structures capable of inducing protective antibodies [52].

In our publication in 2015 we reviewed approaches for the design of third-generation pneumococcal conjugate vaccines based on synthetic oligosaccharide ligands [55]. The studies have been continuing through the recent years; in the current review we consider all pneumococcal serotypes for which synthetic $\mathrm{CP}$ fragments have been produced and immunological studies have been carried out. Particular attention is paid to the most "problematic" CPs of some relevant pneumococcus serotypes with great emphasis on the research conducted in recent years.

\section{S. pneumoniae Serotype 1}

$\mathrm{CP}$ of the highly invasive serotype 1 has a specific chemical structure and contains the rare monosac- charide, 2-acetamido-4-amino-2,4,6-trideoxy-Dgalactose (D-AAT) (1) [64] (Fig. 1). It has been observed that the serotype $1 \mathrm{CP}$ in the pneumococcal vaccines is not effective enough [65]. It was demonstrated that the commercial glycoconjugate vaccine Prevnar $13^{\circledR}$ induces low level of the functional antibodies against the CP of serotype 1 (1) due to the possible modification of the protective $\mathrm{CP}$ epitopes (in particular, amino groups) in the process of chemical activation and conjugation with a protein carrier. Chemical treatment of the CP of serotype 1 (1) could result in its depolymerization causing decrease in the efficiency of the CP (1) in the composition of pneumococcal vaccines. It was established that the risk of destruction of immunogenic epitopes [54, 66] exists during conjugation of the protein carrier with the polysaccharide (1) [54, 66].

Synthetic oligosaccharide antigens can be synthesized using techniques that shield protective epitopes from modifications occurring during the process of its conjugation with the protein carrier. Oligosaccharides (2-5), corresponding to the fragments of the serotype $1 \mathrm{CP}$ chain (Fig. 1), were synthesized by a number of authors [67-71]. The D-AAT residue has been shown to be important for the CP (1) recognition. Thus, it was demonstrated in the experiments involving interaction of the synthetic ligands (2-5) with the serum antibodies against CP (1) that the trisaccharide (4), corresponding to the complete repeating unit, exhibited strongest binding, while the disaccharide (5) containing no D-AAT residue demonstrated much weaker binding, and the monosaccharides (2) and (3) did not bind at all.

Reduction of the disulfide group in the trisaccharide derivative (4) to a thiol and subsequent attachment to the CRM197 protein yielded a glycoconjugate vaccine (6). The amino group in D-AAT was not affected under the used conditions. Immunization of rabbits with the conjugate (6) induced formation of high titers of antibodies specific to CP (1) and trisaccharide (4), as well as antibodies binding directly to DAAT (3). The titers of antibodies to CP (1) upon 


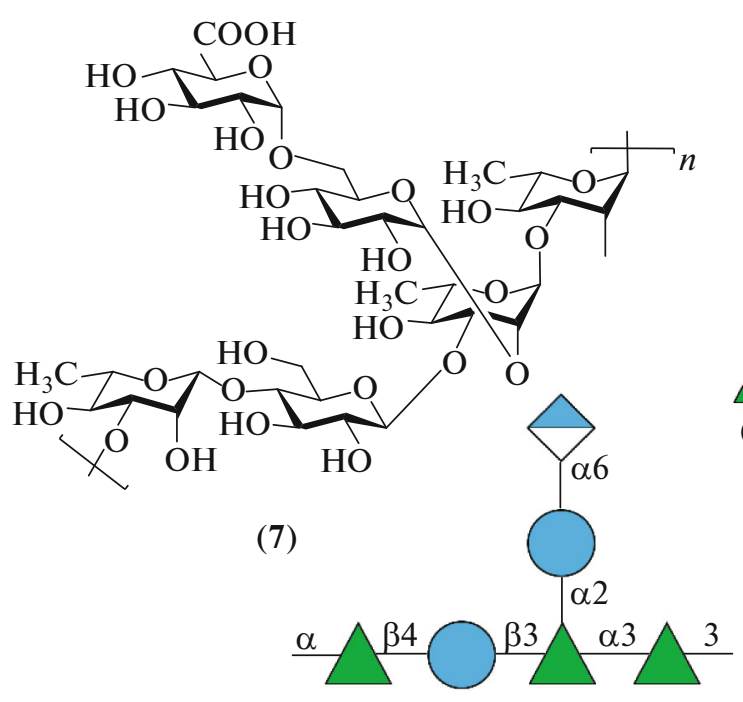

(8)

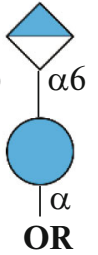

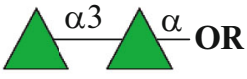

(9)

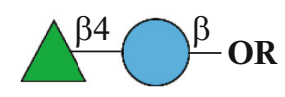

(10)

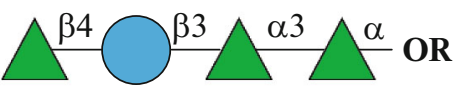

(12)

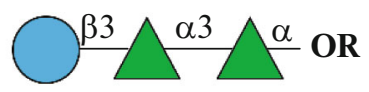

(13)
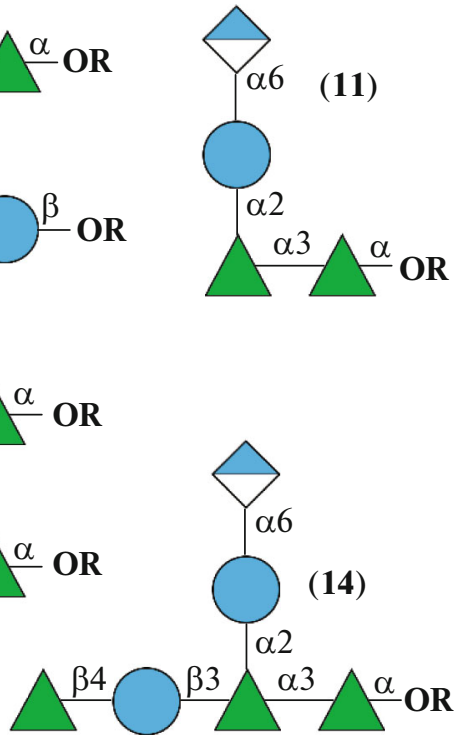

a $\mathbf{R}=\left(\mathrm{CH}_{2}\right)_{3} \mathrm{NH}_{2} \quad$ b $\mathbf{R}=\left(\mathrm{CH}_{2}\right)_{3} \mathrm{NH}-\mathrm{CRM} 197$

Fig. 2. Structure of the capsular polysaccharide of $S$. pneumoniae serotype 2 (repeating unit (7)), synthetic oligosaccharide derivatives $(\mathbf{8 a}-\mathbf{1 4 a})$, and conjugates with $\mathrm{CRM}_{197}$ (series b).

immunization with the conjugate (6) were higher than in the control experiments with the Prevnar $13^{\circledR}$ vaccine [64]. It was demonstrated using flow cytometry that the antibodies induced by the conjugate (6) bound to the serotype 1 pneumococci better than the antibodies generated following immunization with Prevnar $13^{\circledR}$. The antigen-binding capacity of antibodies correlated with the killing activity evaluated by the opsonophagocytic assay. Thus, the pooled serum from the rabbit immunized with the conjugate (6) exhibited higher activity against the serotype 1 pneumococci than the rabbit antiserum produced by immunization with Prevnar $13^{\circledR}$. Moreover, the antibodies induced by the conjugate (6) had higher opsonizing ability than the standard $007 \mathrm{sp}$ serum recommended by the WHO for evaluating efficacy of pneumococcal vaccines [72]. Antibodies to the protein carrier (CRM197) did not bind to the serotype $1 S$. pneumoniae.

The protective activity of immune sera was assessed in the experiments with passive immunization of mice by counting the number of bacterial cells in the blood and in the bronchoalveolar lavage fluid following infection. Sera of rabbits immunized with Prevnar $13^{\circledR}$ and CRM197 were used as control groups. A significant decrease of bacterial load in the blood and bronchoalveolar lavage fluid of infected animals following administration of the conjugate (6) antiserum was observed in comparison with the antisera produced by administration of Prevnar $13^{\circledR}$ and CRM197. Thus, the synthesized conjugate (6) is a promising candidate for inclusion in a vaccine against the $S$. pneumoniae serotype 1 that exhibits superior protective effect in comparison with the conjugate of the corresponding $\mathrm{CP}$ in the composition of the commercial Prevnar $13^{\circledR}$ vaccine [64].

\section{S. pneumoniae Serotype 2}

$S$. pneumoniae serotype 2 belongs to the invasive strains of pneumococcus, but its CP (7) is not included in the commercial pneumococcal conjugate vaccines. To determine the structure of the protective oligosaccharide epitope, a series of fragments $(\mathbf{8 a}-$ 13a) of the repeating unit was synthesized, as well as the hexasaccharide (14a) corresponding to the whole repeating unit of the serotype 2 CP [73] (Fig. 2). It was shown in the experiments on binding of these oligosaccharides to the sera specific to serotype $2 \mathrm{CP}$ (7) that the presence of the $\alpha-D-G l c A-(1 \rightarrow 6)-\alpha-D-G l c-$ $(1 \rightarrow 2)$ side chain $(\mathbf{8 a})$ is necessary for the efficient interaction. A conjugate of the hexasaccharide (14a) with CRM197 (14b) was produced that stimulated Tdependent and B-cell response leading to formation of opsonizing antibodies in mice that mediated killing of the encapsulated bacteria due to increased activity of phagocytes. Subcutaneous immunization with glycoconjugate (14b) protected mice from intranasal infection with a highly virulent serotype 2 strain NCTC 7466, reducing bacterial load in the lung tissues and blood [73].

\section{S. pneumoniae Serotype 3}

$\mathrm{CP}$ of this pneumococcal serotype (15) are characterized by low immunogenicity [52, 53, 74]. According 

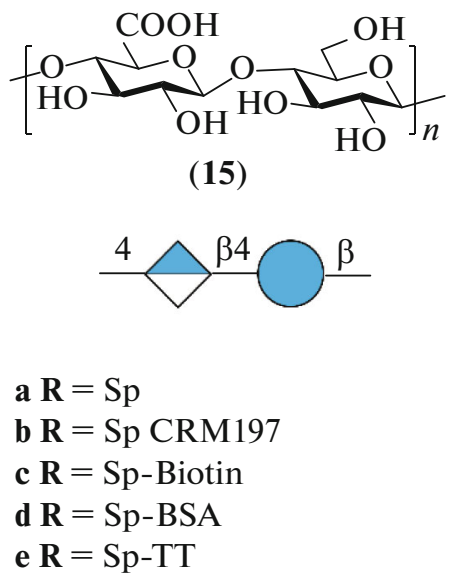

(16)

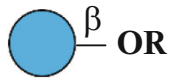

(17)

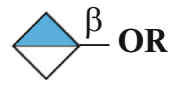

(18)

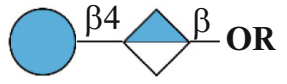

(19)

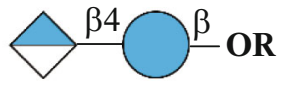

(23)

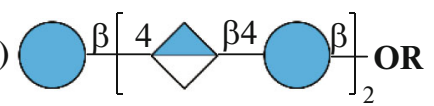

(25)

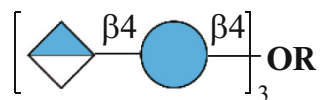

(20)

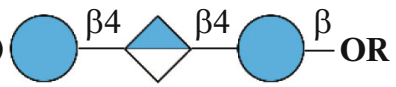

(21)
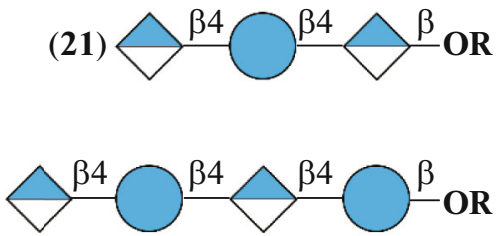

(22)

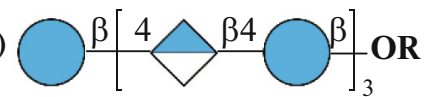

(26)

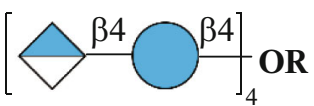

Fig. 3. Structure of the capsular polysaccharide of $S$. pneumoniae serotype 3 (repeating unit (15)), synthetic oligosaccharide derivatives (16-26), and glycoconjugates based thereon (series $\mathbf{b}-\mathbf{e})$.

to Choi et al. [75], one of the reasons for low immunogenicity of the serotype $3 \mathrm{CP}(\mathbf{1 5})$ is the unusual way of its biosynthesis (Fig. 3). The mechanism of CP synthesis has been established for all 94 known pneumococcal serotypes. Two pathways of CP synthesis have been identified: the synthase-dependent and wzydependent [76-79]. The main difference between them is the fact that CP is covalently bound to peptidoglycan of the bacterial cell wall in the wzy-dependent synthesis, while in the synthase-dependent pathway it can be detached from the cell wall. For the majority of $S$. pneumoniae serotypes, CP synthesis occurs via the wzy-dependent pathway, and only two serotypes (3 and 37) synthesize their CPs via the synthase-dependent pathway $[77,80]$. The $S$. pneumoniae serotype 37 is extremely rare in humans, while the serotype 3 is clinically significant [81]. It was shown that the $S$. pneumoniae serotype $3 \mathrm{CP}$ (15) could be found simultaneously in the state associated with the bacterial wall and in a dissolved state in the culture medium [82]. When the $S$. pneumoniae serotype 3 is cultured in vitro and in the course of mice infection, larger amounts of $\mathrm{CP}$ are released into the environment compared to the other pneumococcal serotypes, which results in the reduced antibody-dependent killing of bacteria and decrease in the protection against infection due to the binding of antibodies to free CP. It is also possible that the $\mathrm{CP}$ with bound antibodies could detach from the bacteria and enter circulation, thus reducing protective efficacy of the antibodies.

Changes in the structure of bacterial CP of the $S$. pneumoniae serotype 3 (15) may affect the quality of vaccine preparations. Use of synthetic oligosaccharides - fragments of $S$. pneumoniae serotype $3 \mathrm{CP}(\mathbf{1 5})$ conjugated to a protein carrier - is a promising strategy that could help to mitigate this issue.

Studies on the synthesis of CP fragments of pneumococcal serotype 3 (15) were actually the first investigations in the field of the carbohydrate-based semisynthetic conjugate vaccines [55]. It has been shown that the presence of a glucuronic acid residue in the vaccine conjugate is required for the development of protective immunity $[55,83]$. Later, the conjugates of synthetic monosaccharides (16a) and (17a), disaccharide (19a), trisaccharide (20a), and tetrasaccharide (22a) with the $\mathrm{CRM}_{197}$ protein carrier were produced that corresponded to the fragments of repeating units of the S. pneumoniae serotype 3 CP [61] (Fig. 3). All mice immunized with the synthesized conjugates (20b) and (22b) produced IgG antibodies capable of binding to the CP (15). Comparable titers of specific antibodies in the case of the disaccharide ligand conjugate (19b) were observed in $75 \%$ of the mice studied. All animals with serum containing antibodies to $\mathrm{CP}$ (15) survived infection with the lethal dose of S. pneumoniae serotype 3 . Thus, it was confirmed that the disaccharide fragment (19) is sufficient for the development of protective immunity to the serotype 3 pneumococci in mice.

It should be noted that, unlike in mice, longer oligosaccharides are required to induce optimal immune response in humans, primarily because conformational epitopes are better presented to the immune cells in this case [84]. At the same time, the possibility 
of inducing a T-dependent immune response increases with the decrease in the length of the oligosaccharide chain. Therefore, for best presentation, oligosaccharide epitopes should have both: immunogenic conformation and optimal length. Hence, the length of oligosaccharides should be, on the one hand, sufficient for the expression of conformational epitopes, and on the other hand, not too large for induction of the T-dependent antibody response [30].

In another study, a group of ligands (16a-22a) was synthesized and immobilized on a substrate forming a glycoarray. Using this tool, an automated screening (Glucan Array Assay) of two protective monoclonal antibodies (mAb) specific to $S$. pneumoniae serotype 3 CP (15) was carried out [62]. Both antibodies recognized $S$. pneumoniae serotype $3 \mathrm{CP}$ during the automated screening, and the best binding of both mAbs was observed for the tetrasaccharide (22a). Binding of the tested mAbs to the trisaccharides (20a) and (21a) was slightly weaker, and difference in the binding specificity between the two mAbs was observed. However, none of the mAbs bound disaccharides (18a) and (19a). Therefore, further studies were carried out with the tetrasaccharide conjugate (22b) as a vaccine candidate.

Immunization with the conjugate (22b) led to production of the protective antibodies, which was demonstrated by testing opsonization capacity of the serum and in the murine model of experimental pneumonia with passive immunization of mice followed by infection initiated by intranasal administration of $S$. pneumoniae serotype 3 . According to the MALDITOFF mass spectrometry data, the conjugate (22b) contained on average six tetrasaccharide haptens per CRM197 molecule [85]. To determine immunogenicity of the tetrasaccharide, mice were immunized subcutaneously with an interval of 28 days with two doses of the glycoconjugate (22b) with Freund's adjuvant or with aluminum hydroxide. The use of aluminum hydroxide is preferred over aluminum phosphate, which is included in glycoconjugate vaccines, because at neutral $\mathrm{pH}$ the hydroxide better adsorbs the CRM197 conjugate that contains negatively charged $S$. pneumoniae serotype 3 oligosaccharides [86].

The immunized mice developed IgG antibodies that bound specifically to the tetrasaccharide (22c), demonstrating immunogenicity of the selected ligand. The switch of the immune response from IgM to IgG in response to administration of the booster dose indicated formation of the T-dependent immune response. However, immunogenicity of the conjugated tetrasaccharide largely depended on the adjuvant used. The glycoconjugate (22b) with the Freund's adjuvant induced formation of a higher titer of antibodies compared to the use of the aluminum hydroxide adjuvant [62].

The serum derived from the mice immunized with the conjugate (22b) caused dose-dependent killing of pneumococci, demonstrating that the glycoconjugate induced formation of opsonizing antibodies. The titer of antipneumococcal antibodies, as well as opsonophagocytic activity, depended on the adjuvant used. The Freund's adjuvant caused formation of the higher titer of antibodies with high killer activity in the opsonophagocytosis test compared with the use of aluminum hydroxide. Protective activity of the tetrasaccharide conjugate (22b) against pneumococcal pneumonia was studied using a known model [87, 88].

Since Freund's adjuvant is not used in the vaccine design, the authors introduced the glycoconjugate (22b) adsorbed on aluminum hydroxide or without an adjuvant. Immunization with the conjugate (22b) adsorbed on aluminum hydroxide significantly reduced severity of the disease. Pneumococcal pneumonia significantly increased lung permeability in the control animals and in the mice immunized with the conjugate (22b) without adjuvant. The use of the conjugate (22b) adsorbed on aluminum hydroxide preserved integrity of the alveolar barrier, reduced bacterial load in the lungs, and almost completely prevented development of bacteremia in the tested animals in comparison with the animal in control group and the group immunized with the glycoconjugate (22b) without an adjuvant. Antibacterial protection was accompanied by the increase in the number of leukocytes and decrease in the production of cytokines in the alveolar compartment of the mice with pneumococcal infection. Induction of the long-term immunity is an important indicator of successful vaccination. After 4 months, protection against the infection was lower than at the time of infection on the 35th day after immunization. Additional trials are being conducted to investigate ability of the conjugate (22b) to induce long-term immune protection against the serotype 3 pneumococci. It was shown previously that in some cases the development of long-term immune memory requires the use of longer carbohydrate ligands [62].

The authors of this review also synthesized oligosaccharides (19a), (20a), and (22a) and their conjugates with biotin, (19c), (20c), and (22c), respectively (the article is in preparation for publication). It was shown that the biotinylated derivatives (19c), (20c), and (22c) immobilized on the streptavidin-coated microplates, stimulated production of IL-1 $\alpha$, IL-2, IL-4, IL-5, IL-10, IFN $\gamma$, IL-17A, and TNF $\alpha$, but not IL-6 or GM-CSF, in the monoculture of mouse splenocytes. The tetrasaccharide conjugate (22c) most effectively stimulated production of IL-4, IL-5, IL10 , and IFN $\gamma$, which promoted expression of the specific immunoglobulin isotypes. The BSA conjugate (22d) adsorbed on aluminum hydroxide caused formation of high levels of $\operatorname{IgM}, \operatorname{IgG} 1, \operatorname{IgG} 2 \mathrm{a}$, and $\mathrm{IgG} 2 \mathrm{~b}$ antibodies. The content of anti-CP-induced antibodies could only be determined using the biotinylated tetrasaccharide (22c). The conjugate (22d) exhibited the highest ability to bind IgG antibodies in the mouse antiglycoconjugate sera and rabbit antibacterial 


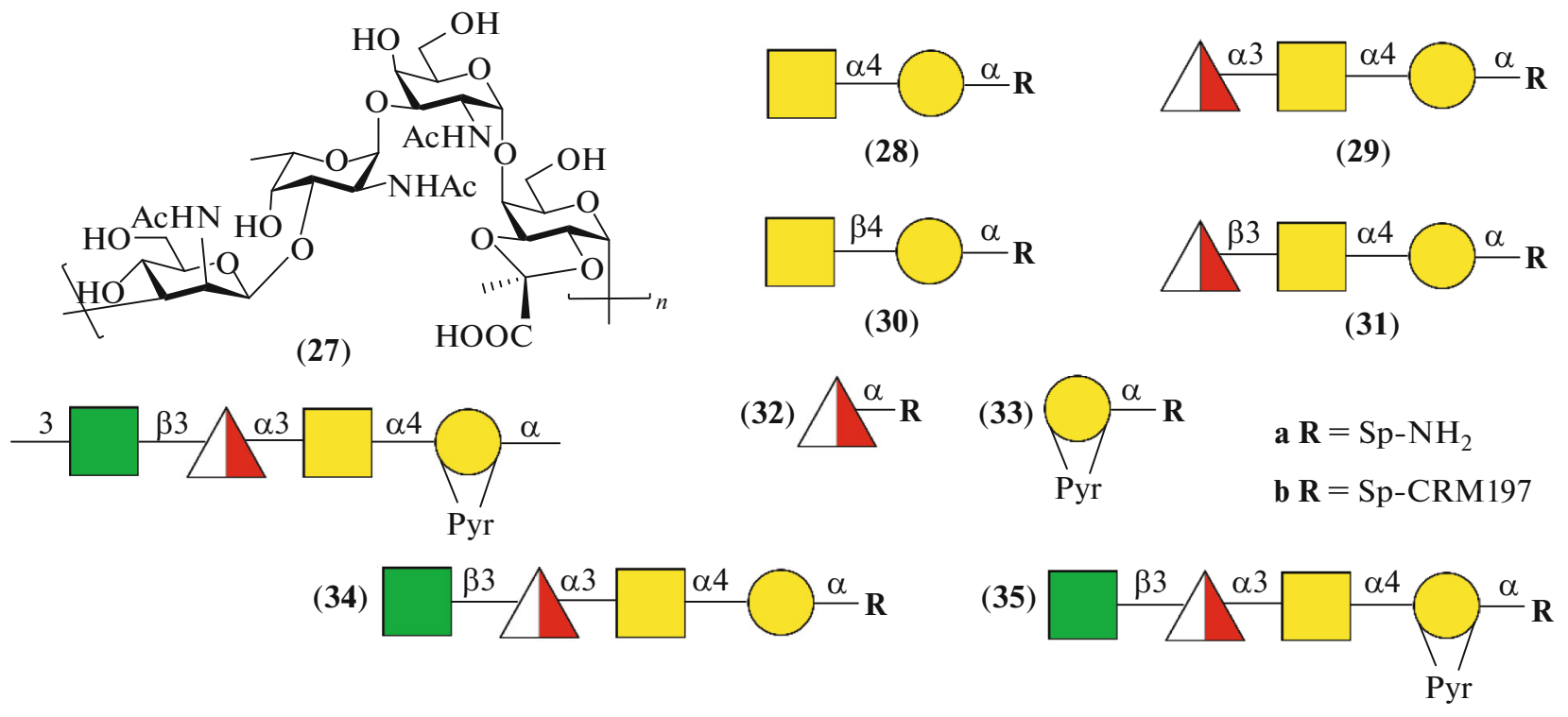

Fig. 4. Structure of the capsular polysaccharide of $S$. pneumoniae serotype 4 (repeating unit (27)), synthetic oligosaccharide derivatives (28a-35a), and conjugates with CRM197 (series b).

serum. The sera to the conjugate $(\mathbf{2 2 d})$ promoted higher phagocytosis of bacteria by neutrophils and monocytes compared to the serum to the CP (15)CRM197 conjugate. The serum of mice immunized with the tetrasaccharide conjugate (22d) showed the highest titer of IgG1 antibodies against CP compared to the sera of mice immunized with the same doses of di- (19d) and trisaccharide (20d) conjugates. The degree of protection of mice infected with a lethal dose of $S$. pneumoniae serotype 3 by the tri- (20d) and tetrasaccharide (22d) conjugates was higher than the degree of protection provided by the disaccharide conjugate (19d). It was shown based on the conducted studies that the tetrasaccharide ligand (22a) is an optimal candidate for the development of semisynthetic vaccine against the $S$. pneumoniae serotype 3 and diagnostic test systems.

Longer fragments of the serotype 3 CP (15) were synthesized, including up to four repeating units of this polysaccharide (compounds (23a-26a)) [89]. Among these ligands, there were oligosaccharides containing either glucose residue (23a, 24a) or glucuronic acid residue (25a, 26a) at the nonreducing end. Conjugates of these compounds with BSA (23d-26d) and tetanus toxoid $(\mathbf{2 3 e}-\mathbf{2 6 e})$ were obtained. The conjugates (23e-26e) and free oligosaccharides (23a26a) were used to immunize mice, while BSA-conjugates (23d-26d) were used as coating antigens in the analysis of sera obtained after immunizations by ELISA. Sera of mice immunized with the tetanus toxoid conjugates $(\mathbf{2 3 e}-\mathbf{2 6 e})$ contained much higher titers of specific antibodies than the antisera against free oligosaccharides (23a-26a). It should be mentioned that the titers of specific antibodies induced by penta- and hexasaccharide conjugates (23e and 25e, respectively) significantly exceeded the titers obtained in the case of octa- and heptasaccharide conjugates (24a and 26a, respectively), which indicated that the further increase in the length of carbohydrate ligands adversely affected immunological properties of the conjugates [89].

\section{S. pneumoniae Serotype 4}

Structure of the pneumococcus serotype 4 CP (27) contains a rare and labile substituent (cyclic pyruvate ketal) at the reducing end of the terminal galactose residue. Recently, Seeberger et al. synthesized a large set of fragments of this polysaccharide (28a-35a) (Fig. 4), among which there were oligosaccharides of varying lengths, as well as compounds designed to establish whether the presence of the pyruvate substituent was essential $[90,91]$.

Antibodies in the reference human serum specific to CP of serotype 4 (27) recognized both oligosaccharides containing pyruvate fragment and oligosaccharides with unsubstituted galactose residues equally. The tetrasaccharide (35a) exhibited the highest affinity and cross-reactivity with respect to CP (27) in the study of sera from mice and humans immunized with the CP of serotype 4 (27). Since the antibodies from the human serum also recognized oligosaccharides without the pyruvate substituent $(\mathbf{2 9 a}, \mathbf{3 4 a})$, the researchers suggested that the natural $\mathrm{CP}$ might also contain units that do not carry pyruvate substituent in the galactose residue. However, the pyruvate-free epitopes could be less immunogenic, as demonstrated by the weaker binding of antibodies to the oligosaccharides (29a) and (34a) compared to the tetrasaccharide (35a) containing pyruvate. To test this hypothesis, the 


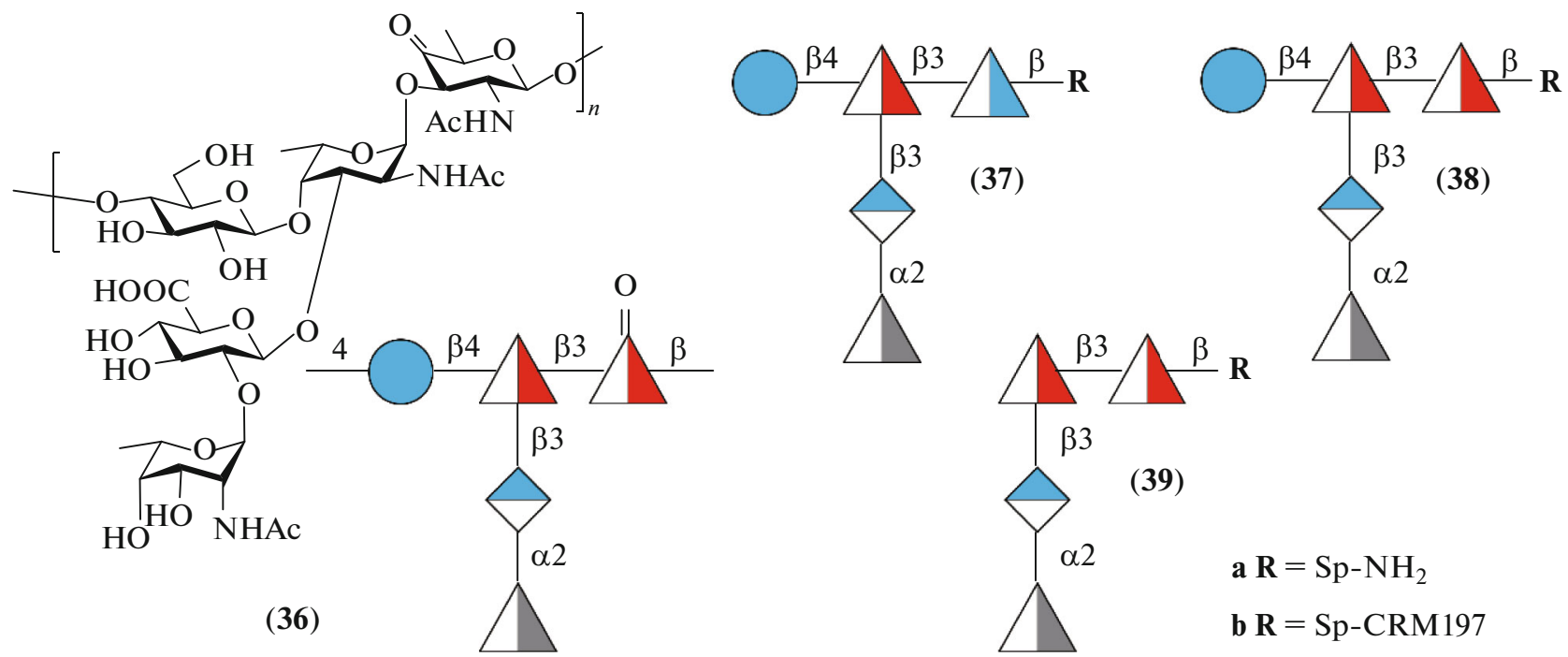

Fig. 5. Structure of the capsular polysaccharide of $S$. pneumoniae serotype 5 (repeating unit (36)), synthetic oligosaccharide derivatives (37a-39a), and conjugates with CRM197 (series b).

conjugates (29b) and (34b) were synthesized with ligands not containing the pyruvate substituent. Antibodies obtained upon immunization of mice with the conjugates (29b) and (34b) did not recognize CP of serotype 4, which indicated significance of the pyruvate presence for the development of the specific immunity $[90,91]$.

\section{S. pneumoniae Serotype 5}

The serotype 5 causes invasive pneumococcal diseases in children worldwide [11, 92]. Commercial glycoconjugate vaccines are produced from the native or depolymerized CP [93] conjugated to a carrier protein. However, they were shown to be insufficiently effective in the prevention of infections caused by the serotype 5 [94]. The repeating unit of the serotype 5 CP (36) (Fig. 5) contains two rare monosaccharide residues: 2-acetamido-2,6-dideoxy-D-xylosehexose-4-ulose (Sugp) and $N$-acetyl-L-pneumosamine (L-PneupNAc). CP of the serotype 5 (36), as well as $\mathrm{CP}$ of the serotype 1 (1) seems to be a weak point in the existing pneumococcal vaccines (it is included in the 10- and 13-valent vaccines), because the keto group of the Sugp residue undergoes partial or complete reduction during its isolation from bacterial sources and purification in the course of the conjugate vaccine production. That is why the resulting product is a heterogeneous mixture with reduced immunogenicity compared to the native CP of the serotype $5(36)[95,96]$.

The preliminary studies with a large group of mono- and disaccharide fragments of the repeating unit of the polysaccharide (36) and the standard rabbit and human sera for pneumococcal serotyping have shown that the GlcA-PneuNAc branch is most important for recognition [95]. Attempts to synthesize the repeating unit of the $\mathrm{CP}$ (36) were unsuccessful due to extreme instability of the keto group in the Sugp residue that creates problems for the product isolation and purification.

According to the automated screening data, the Sugp residue is not immunodominant; therefore, more stable oligosaccharides with the reduced keto group (37a-39a) were synthesized to design conjugate vaccines: two of the oligosaccharides $(\mathbf{3 8 a}, 39 \mathbf{3})$ contained a fucosamine residue, and the tetrasaccharide (37a) had a quinavosamine residue at the reducing end [95] (Fig. 5). Antibodies in the serotype 5 CP specific sera (36) (rabbit and human sera for typing of this serotype were used, as well as rabbit antiserum to the Prevnar $13{ }^{\circledR}$ vaccine), bound well to both pentasaccharides $(\mathbf{3 7 a}, \mathbf{3 8 a})$ and slightly worse to the tetrasaccharide (39a).

Since chemical synthesis of the ligand (37a) was rather laborious, only conjugates (38b) and (39b) were obtained for immunological experiments. The conjugate $\mathbf{( 3 8 b )}$ stimulated formation of higher titers of the cross-reactive antibodies in rabbits than the tetrasaccharide conjugate (39b). Antisera induced by the conjugate (38b) recognized pentasaccharide (37a) and CP (36) in addition to the pentasaccharide ligand (38a) itself. These data emphasize that the full repeating unit of the CP of serotype 5 (36) is required to obtain an immunogenic conjugate vaccine conjugate.

Both conjugates $(\mathbf{3 8 b}, \mathbf{3 9 b})$ induced formation of antibodies in rabbits with higher opsonizing capacity than the antibodies induced in response to the multivalent vaccine Prevnar $13^{\circledR}$; furthermore, the antibodies against the pentasaccharide in the conjugate (38b) demonstrated stronger antibacterial effect in vitro than the antibodies against the tetrasaccharide conjugate (39b). However, protective functions of antisera are 
determined not only by the titers of opsonizing antibodies, but also by their avidity to the native $\mathrm{CP}$ on the surface of bacteria. The quantitatively determined avidity values for the CP (36) in the tests with inhibition of binding by ammonium cyanate showed that avidity of the antibodies induced by conjugate (38b) was more than four times higher than avidity of the antisera against both the conjugate (39b) and the Prevnar $13^{\circledR}$ vaccine.

Although comparable doses of the semisynthetic conjugates (38b) and (39b) and of the conjugate of the serotype $5 \mathrm{CP}(\mathbf{3 6})$ in the Prevnar $13^{\circledR}$ vaccine have been used, it could be possible that the presence of additional serotypes in the multivalent vaccine reduced activity of the individual CPs of other serotypes, and therefore such comparison is not quite correct [97, 98]. Efficient vaccines should lead to the development of long-term immune response and formation of memory B cells. In this study, the titers of specific antibodies in the rabbits immunized with the conjugate (38b) decreased by the 119th day after primary immunization; however, administration of the booster dose led to a rapid increase in the level of antibodies, which indicated strong immunological memory. Thus, the pentasaccharide conjugate $\mathbf{( 3 8 b )}$ is a promising candidate for a vaccine against the serotype 5 pneumococci.

\section{S. pneumoniae Serotype 6}

$S$. pneumoniae serotype $6 \mathrm{~B}$ is a common cause of pneumococcal disease, especially in children [99, $100]$, and is also associated with antibiotic resistance [101-103]. CP of S. pneumoniae serotype 6B (41) (Fig. 6) is included in the first generation of the 23valent polysaccharide vaccines Pneumovax $23^{\circledR}$ (Merck Sharp \& Dohme Corp.) and Pneumo $23^{\circledR}$ (Sanofi), as well as all pneumococcal conjugate vaccines currently being produced. The CP (41) contains a phosphate group, and its conjugation with a carrier protein is not always successful. Antibodies induced by the $\mathrm{CP}(\mathbf{4 1})$ are characterized with slow affinity maturation compared to the $\mathrm{CP}$ of other pneumococcal serotypes [104], and therefore the amount of CP of the pneumococcal serotype 6B (41) in the conjugate vaccines is doubled compared to the CPs of other serotypes. The $S$. pneumoniae serotype 6B belongs to the serogroup 6, which includes three more serovariants with polysaccharides differing only slightly: 6A (40), 6C (42), and 6D (43) (Fig. 6); however, the $S$. pneumoniae serotypes $6 \mathrm{~A}$ and $6 \mathrm{~B}$ are of the greatest clinical importance.

Due to insignificant structural differences between the CPs of serogroup 6, the antibodies to CP of S. pneumoniae serotype 6B exhibit cross-reactivity with the $S$. pneumoniae serotypes $6 \mathrm{~A}, 6 \mathrm{D}$, and $6 \mathrm{C}$ [105-107]. This is confirmed by the fact that the cases of diagnosis of the serotype 6A became less frequent after the start of the widespread use of the pneumococcal conjugate vaccine containing $\mathrm{CP}$ from the serotype 6B [55]. However, this may also be due to the fact that gene mutations could result in the synthesis of several types of repeating units within a single CP. In particular, the pneumococci were discovered producing "mixed" CP of the serotype 6A/6B [108], which depended on the $\mathrm{CP}$ producer strain, composition of the nutrient medium, and cultivation conditions of the S. pneumoniae strains.

The synthetic CP analogs conjugated to a protein carrier that contain protective epitopes of the corresponding pneumococcal serotypes can lead to the formation of higher titers of specific antibodies than the conjugates of the natural bacterial CPs $[109,110]$. This was also demonstrated using oligosaccharides corresponding to the fragments of the CP chain of $S$. pneumoniae serogroup 6, synthesis of which was carried out by several research laboratories. Oligosaccharides with the size not less than a full repeating unit were the most active ones [55]. For example, the tetrasaccharides (44a) and (45a) containing phosphates, as well as tetrasaccharides without a phosphate group (46), (47), and (48) (Fig. 6) were synthesized, imitating the repeating units of CPs of serotypes $6 \mathrm{~A}, 6 \mathrm{~B}$, and $6 \mathrm{C}$, respectively [111-113]. The conjugate of the phosphate-containing tetrasaccharide with the KLH protein (44b) induced formation of antibodies capable of cross-reacting with the CPs of both serotypes 6B (41) and $6 \mathrm{~A} \mathrm{(40)}$ in mice and rabbits, as well as stimulating phagocytosis of microbial cells of pneumococcus serotypes 6A and 6B [60].

The experiments on passive and active immunization of mice demonstrated that the rabbit antiserum against the conjugate $\mathbf{( 4 4 b )}$ protected mice from infection with pneumococcus serotypes $6 \mathrm{~A}$ and $6 \mathrm{~B}$. This led to conclusion that the tetrasaccharide (44a) conjugated to a protein carrier (conjugate (44b)) could be an effective vaccine component capable of inducing the protective antibodies to $S$. pneumoniae serotypes 6A and 6B [60]. The contradicting results were obtained in the study of the tetrasaccharide (46a) without phosphate group. The $\mathrm{CP}$ of serotype $6 \mathrm{~B}$ did not inhibit interaction of the rabbit antibodies with the conjugate (46b). This may mean that the epitopes presented in the CP of serotype $6 \mathrm{~B}$ differ from those presented in the unphosphorylated tetrasaccharide (46a) [114116]. Thus, it is necessary to use the phosphate-containing tetrasaccharides corresponding to the repeating unit of the $\mathrm{CP}$ of $S$. pneumoniae serogroup 6A and $6 \mathrm{~B}$ to obtain an effective conjugate vaccine against the $S$. pneumoniae serotype 6 .

\section{S. pneumoniae Serotype $7 F$}

Until 2012, the $S$. pneumoniae serotype 7F was the fifth most common serotype among 97 serotypes causing invasive pneumococcal diseases in Europe; however, the number of pneumonia cases caused by 

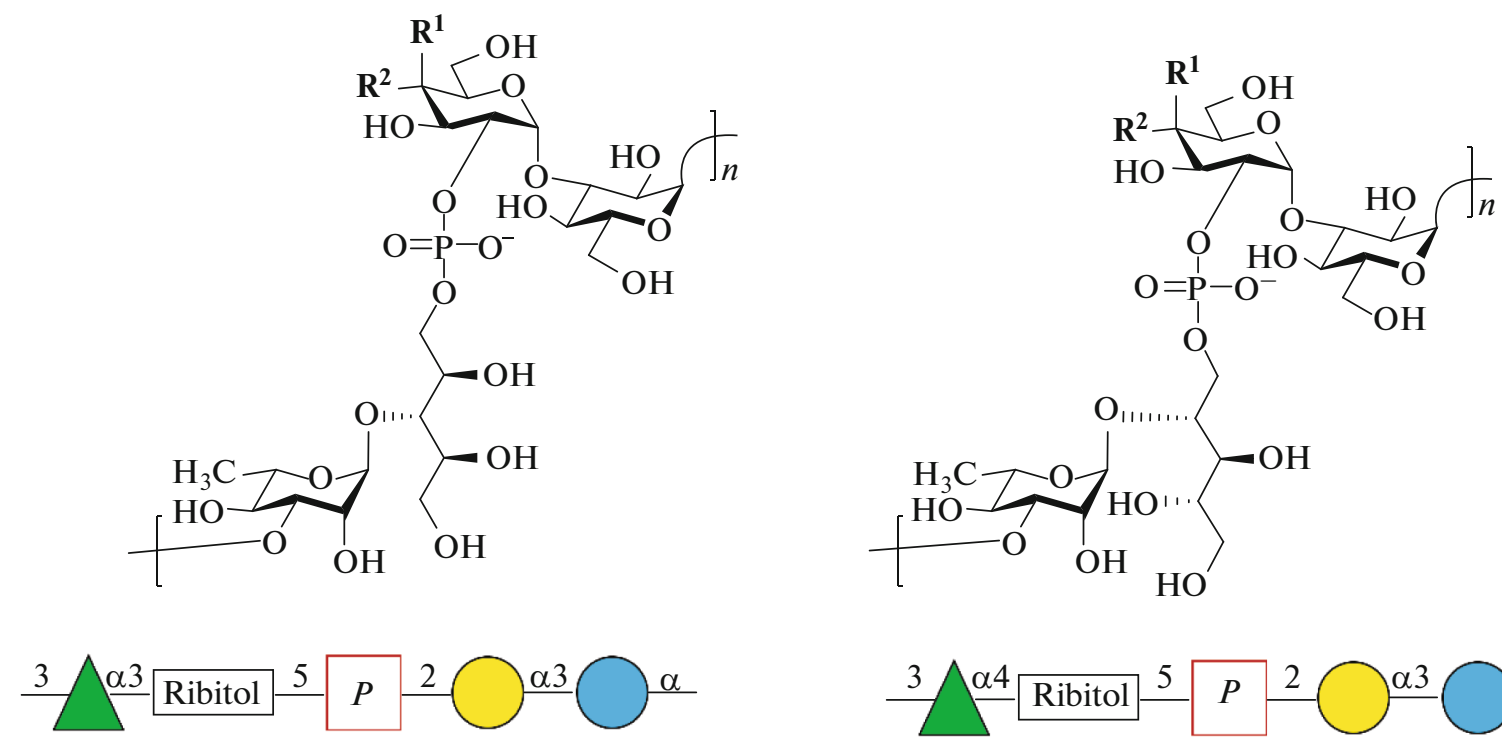

(40) (6A): $\mathbf{R}^{1}=\mathrm{OH}, \mathbf{R}^{2}=\mathrm{H}(D-\mathrm{Gal})$

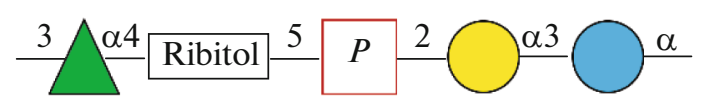

(41) (6B): $\mathbf{R}^{1}=\mathrm{OH}, \mathbf{R}^{2}=\mathrm{H}(D-\mathrm{Gal})$

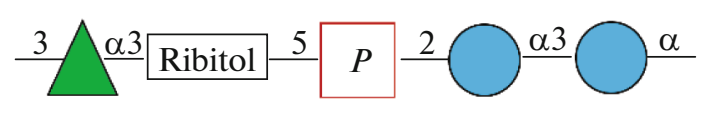

(42) (6C): $\mathbf{R}^{1}=\mathrm{H}, \mathbf{R}^{2}=\mathrm{OH}(D-\mathrm{Glc})$

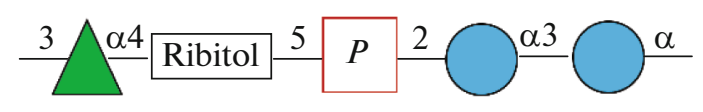

(43) (6D): $\mathbf{R}^{\mathbf{1}}=\mathrm{H}, \mathbf{R}^{2}=\mathrm{OH}(D-\mathrm{Glc})$

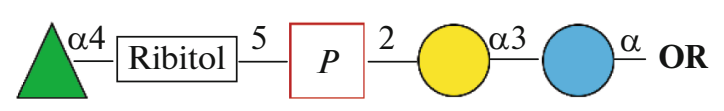

(44)

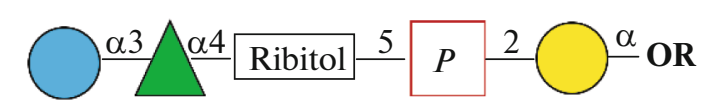

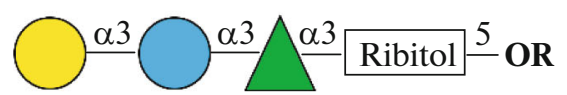

(46)

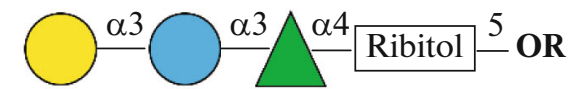

(47)

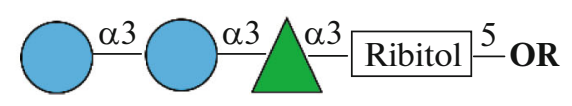

(48)

Fig. 6. Structures of the capsular polysaccharide of $S$. pneumoniae serotypes 6A, 6B, 6C, and 6D (repeating units (40-43)), synthetic oligosaccharide derivatives (44a-48a), and conjugates with KLH (series b) and BSA (series c).

this serotype decreased with introduction of the 13-valent vaccine, which includes $\mathrm{CP}$ of serotype $7 \mathrm{~F}$ (49) (Fig. 7) [117]. The repeating unit of CP (49) contains seven monosaccharide residues, four of which are in the main chain, and there are also two branches. To determine the minimal glycotope capable of inducing formation of the specific immune response against the $\mathrm{CP}$ of serotype 7 (49) a number of spacer-conjugated oligosaccharides (51-56) [117] were synthesized with structures selected in such a way that contribution of each of the branches into interaction with the specific antibodies could be evaluated. The heptasaccharide corresponding to the complete repeating unit was not synthesized due to the difficulties of introducing the $\alpha-N$-acetylglucosamine residue. 


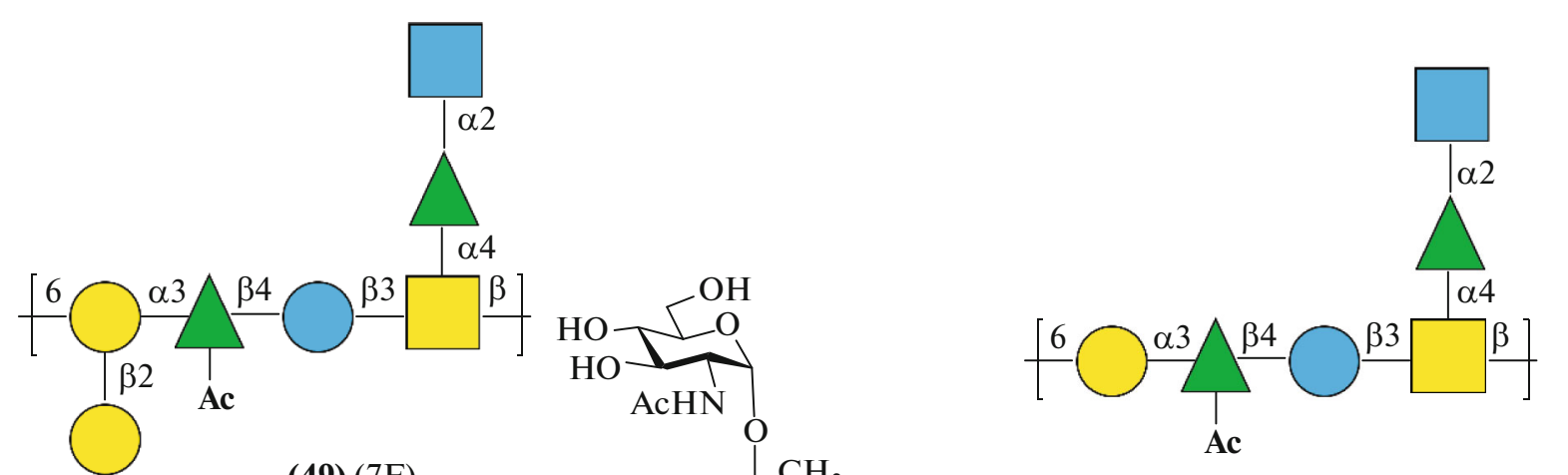

(49) $(7 \mathrm{~F})$

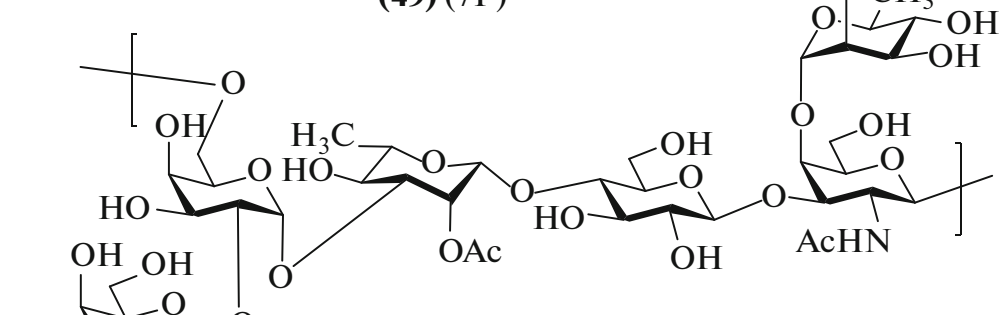

(50) $(7 \mathrm{~A})$

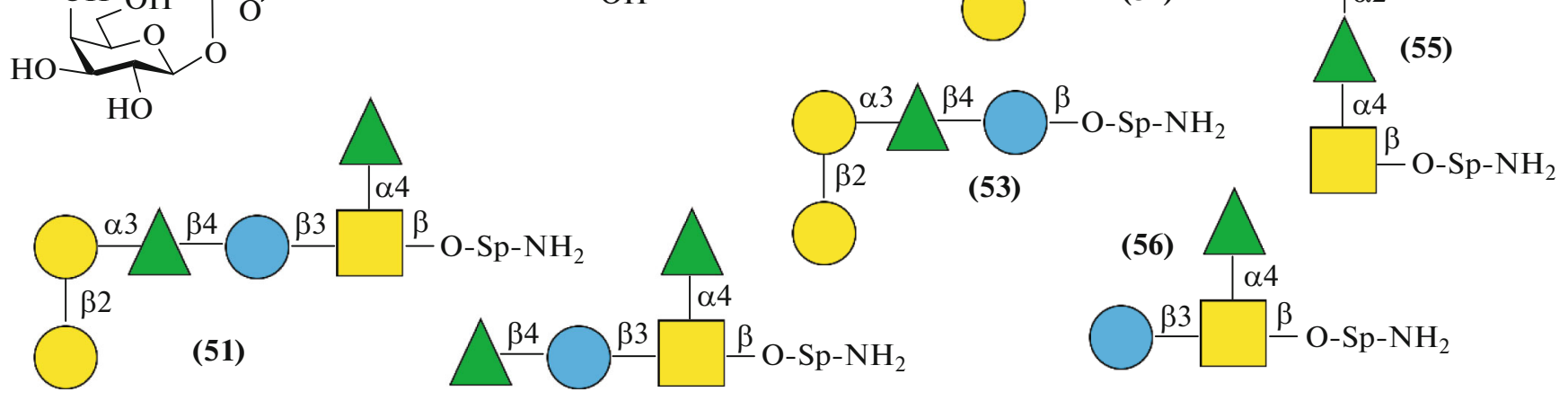

(52)

Fig. 7. Structure of the capsular polysaccharide of $S$. pneumoniae serotype 7F (repeating unit (49)) and synthetic oligosaccharide derivatives $(\mathbf{5 0}-\mathbf{5 6})$.

To identify the epitopes responsible for binding to human antibodies, an automated microsystem was used to study interactions of oligosaccharides (51-56) with antibodies from the reference human serum 007sp [72]. This serum bound to the oligosaccharides (51-55), but did not bind to the trisaccharide (56). Addition of the CP of serotype 7F effectively inhibited interaction of the $007 \mathrm{sp}$ serum with oligosaccharides (51-56) deposited on the microchip surface (the least inhibition was observed in the case of tetrasaccharide (52)). The related CP of serotype 7A (50) lacking galactose residue in the side chain, was also able to inhibit interaction of the serum $007 \mathrm{sp}$ with oligosaccharides (51-56), but to a lesser extent than the CP of serotype $7 \mathrm{~F}$ (49). The authors concluded that both side branches in the structure of the carbohydrate ligand play an important role in recognition by specific antibodies, and this should be taken into account during further design of semisynthetic conjugate vaccine. Cross-reactivity observed in the inhibition experiments suggests that the synthetic antigens represented by the fragments of the serotype 7F CP (49) should induce antibodies to both serotypes 7F and 7A [117].

\section{S. pneumoniae Serotype 8}

The polysaccharide of this serotype is included in the 23 -valent polysaccharide vaccines Pneumovax $23^{\circledR}$ and Pneumo $23^{\circledR}$, but not in the polysaccharide conjugate vaccines released later. The strains of this serotype resistant to antibiotics such as erythromycin, clindamycin, tetracycline, and ciprofloxacin have been identified [118]. Moreover, this multidrug-resistant serotype is most often found in the HIV-infected patients [119].

The repeating unit of CP of the serotype 8 (57) (Fig. 8) is a linear tetrasaccharide that contains a disaccharide fragment corresponding to cellobiuronic acid $[\beta-D-G l c A-(1 \rightarrow 4)-\beta-D-G l c]$, also present in the $\mathrm{CP}$ of the pneumococcal serotype 3 .

To determine structure of the protective epitope, Seeberger et al. synthesized a series of tetrasaccharides (58a-61a) [119] (Fig. 8), including all possible monosaccharide sequences (obtained by shifting the reading frame) for the tetrasaccharide repeating unit CP (57). Automated microanalysis of a panel of antigens $(\mathbf{5 8 a}-$ 62a) showed that the tetrasaccharide (60a) bound best 




Fig. 8. Structure of the capsular polysaccharide of $S$. pneumoniae serotype 8 (repeating unit (57)), synthetic oligosaccharide derivatives (59a-62a), and conjugates with CRM197 (series b).

to the protective monoclonal antibodies against the native CP of serotype 8 (57).

Further mapping of the protective epitopes in the tetrasaccharide (60a) was performed using monoclonal antibodies specific to the ligand (60a) selected after immunization of mice with the conjugate $(\mathbf{6 0 b})$. It turned out that the presence of the glucuronic acid residue does not play a significant role, since the tetrasaccharide (62a) containing glucose residue at the nonreducing end demonstrated binding profile similar to that of the tetrasaccharide (60a). The conjugates $(60 b)$ and (62b) were found to be only weakly immunogenic in mice; however, in rabbits, both conjugates induced high titers of antibodies that bound to both $\mathrm{CP}$ of serotype 8 (57) and tetrasaccharides (60a) and (62a) [119].

Experimental mixed vaccines consisting of the conjugate $(60 \mathrm{~b})$ or $(62 \mathrm{~b})$ adsorbed onto commercial polysaccharide conjugate vaccine Prevnar $13^{\circledR}$ that has no CP of serotype 8 (57) in its composition have also been prepared [119]. In rabbits, both 14-valent vaccine preparations caused formation of the antibodies that bound to CP of serotype 8 (57), which was not the case for immunization with the Prevnar $13^{\circledR}$ vaccine alone. The serum from rabbits immunized with the 14-valent vaccines displayed opsonizing activity against the pneumococci serotype 8 in vitro, unlike the serum from rabbits immunized with Prevnar $13^{\circledR}$ alone. It was also shown that simultaneous administration of the semisynthetic conjugate vaccines $(\mathbf{6 0 b})$ or $(\mathbf{6 2 b})$ and Prevnar $13^{\circledR}$ vaccine did not lead to the decrease in immunogenicity of the $\mathrm{CP}$ in the commercial vaccine [119]. Thus, the possibility to efficiently use the conjugates of synthetic oligosaccharide ligands in combination with the conjugate polysaccharide vaccines has been demonstrated. This may be useful for the most problematic serotypes, CPs of which are not sufficiently active in the vaccines due to the structural features of these polysaccharides.

\section{S. pneumoniae Serotype $9 \mathrm{~V}$}

$\mathrm{CP}$ of the pneumococcal serotype 9V (64) (Fig. 9) is included in the Prevnar $13^{\circledR}$ vaccine. The structure of this CP contains a labile $O$-acetyl substituent in the $N$-acetylmannosamine residue (see repeating unit (63), which contains no $O$-acetyl group). This fact complicated isolation of the homogeneous polysaccharide from the bacterial sources and for a long time did not allow determination of its chemical structure. Antibodies against the native $\mathrm{CP}(\mathbf{6 4})$ recognize both the $O$-acetylated form (64) and its $O$-deacetylated analog (63). However, only the antiserum recognizing the $O$-deacetylated polysaccharide (63) exhibited opsonophagocytic activity, which indicated that the presence of $O$-acetate in this case is not necessary for the development of protective immunity [120].

In another study [121], monoclonal antibodies to CP of the serotype 9V (64) were shown to bind to both forms (63) and (64) equally; they exhibited opsonophagocytic activity and protected mice from infection with pneumococcus serotype $9 \mathrm{~V}$ upon passive immunization. In order to elucidate the effect of $O$-acetylation of the CP of serotype $9 \mathrm{~V}$ on the specificity of immune response, pentasaccharides with $O$-acetyl group (66) and without one (65) [122] (Fig. 9) were synthesized and studied.

The structures of these compounds, in which there is a glucuronic acid residue at the nonreducing end, were selected based on the results of studies of oligosaccharides related to $\mathrm{CP}$ of the serotypes 3 and 8 , in which the presence of the very terminal glucuronic acid residue was found to be crucial for recognition by antibodies specific to the corresponding CP. Presence of the $O$-acetyl group at $\mathrm{C} 6$ of the $\mathrm{N}$-acetylmannosamine residue in the native polysaccharide (64) was spectrally confirmed with the help of the synthesized analogues, and these oligosaccharides will now be used for immunological studies [122]. 


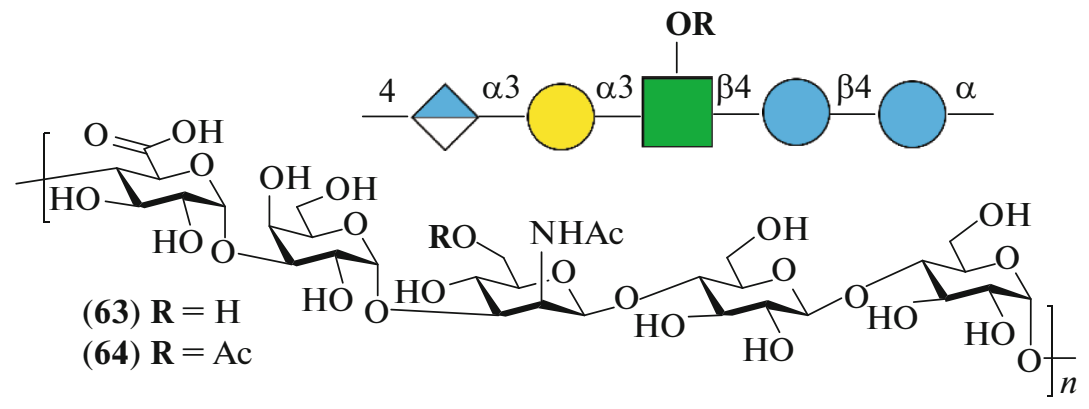

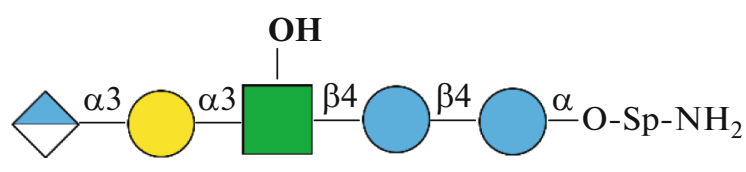

(65)

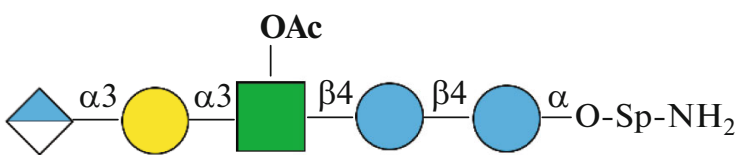

(66)

Fig. 9. Structure of the capsular polysaccharide of $S$. pneumoniae serotype $9 \mathrm{~V}$ (repeating unit (64)), its $O$-deacetylated derivative (repeating unit (63)), and synthetic oligosaccharide derivatives (65) and (66).

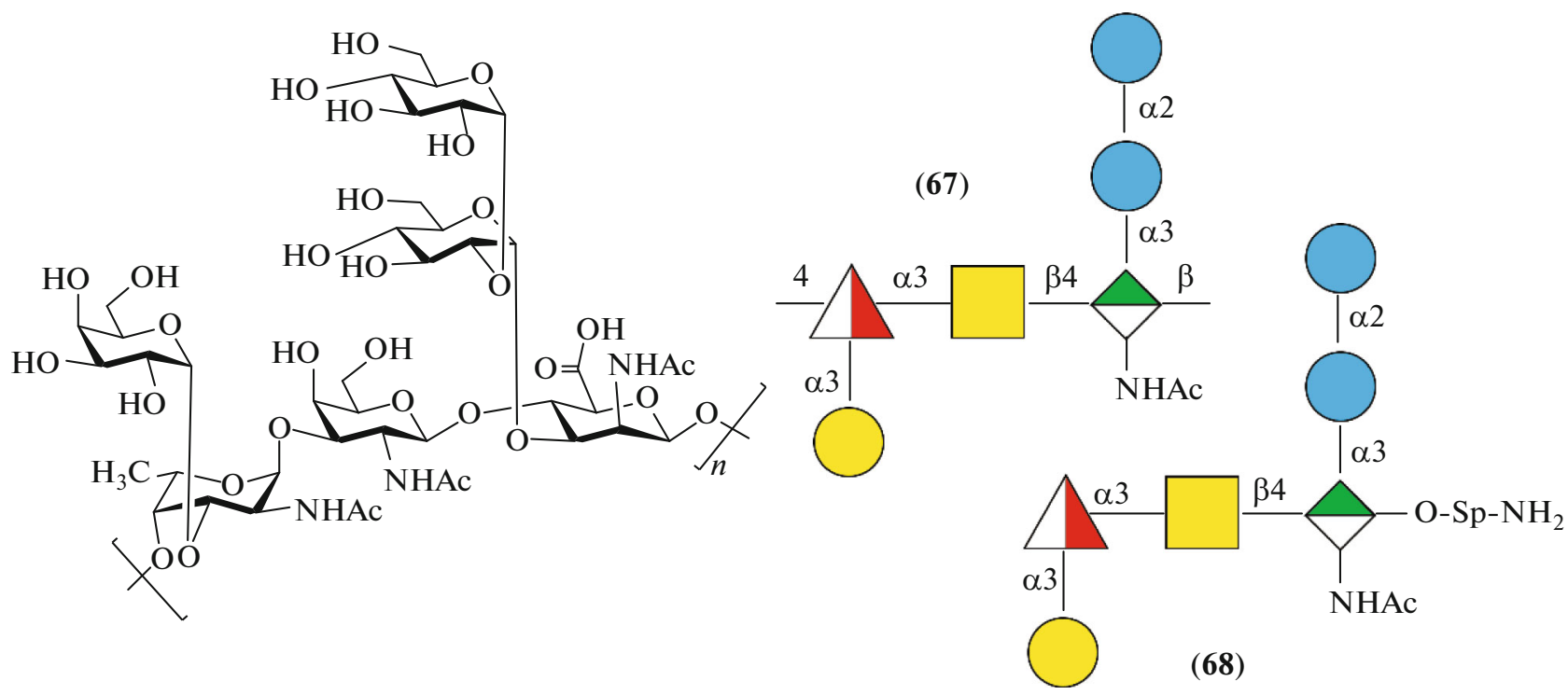

Fig. 10. Structure of the capsular polysaccharide of $S$. pneumoniae serotype $12 \mathrm{~F}$ (repeating unit (67)) and synthetic oligosaccharide derivative (68).

\section{S. pneumoniae Serotype $12 F$}

$\mathrm{CP}$ of the serotype $12 \mathrm{~F}$ is included in the Pneumovax $23^{\circledR}$ and Pneumo $23^{\circledR}$ pneumococcal 23 -valent polysaccharide vaccines and is also a component of the Prevnar $20^{\circledR} 20$-valent polysaccharide conjugate vaccine currently undergoing clinical trials. The serotypes $12 \mathrm{~F}$ and $12 \mathrm{~A}$ together are responsible for $4 \%$ of pneumococcal diseases [3]. A spacer-equipped hexasaccharide (68) comprising a single repeating unit of the polysaccharide (67) was produced for further immunological studies (Fig. 10) [123].

\section{S. pneumoniae Serotype 14}

The capsular polysaccharide of $S$. pneumoniae serotype 14 (69) consists of branched tetrasaccharide repeating units (Fig. 11). To date, a number of synthetic oligosaccharides corresponding to the sections of the CP chain of $S$. pneumoniae serotype 14, including those conjugated with a protein carrier, have been obtained [124-127]. The capsular polysaccharide of the $S$. pneumoniae serotype 14 was also synthesized [125] and used in immunological studies [128, 129].

It was established in the course of investigation of a large group of synthetic oligosaccharide fragments of 


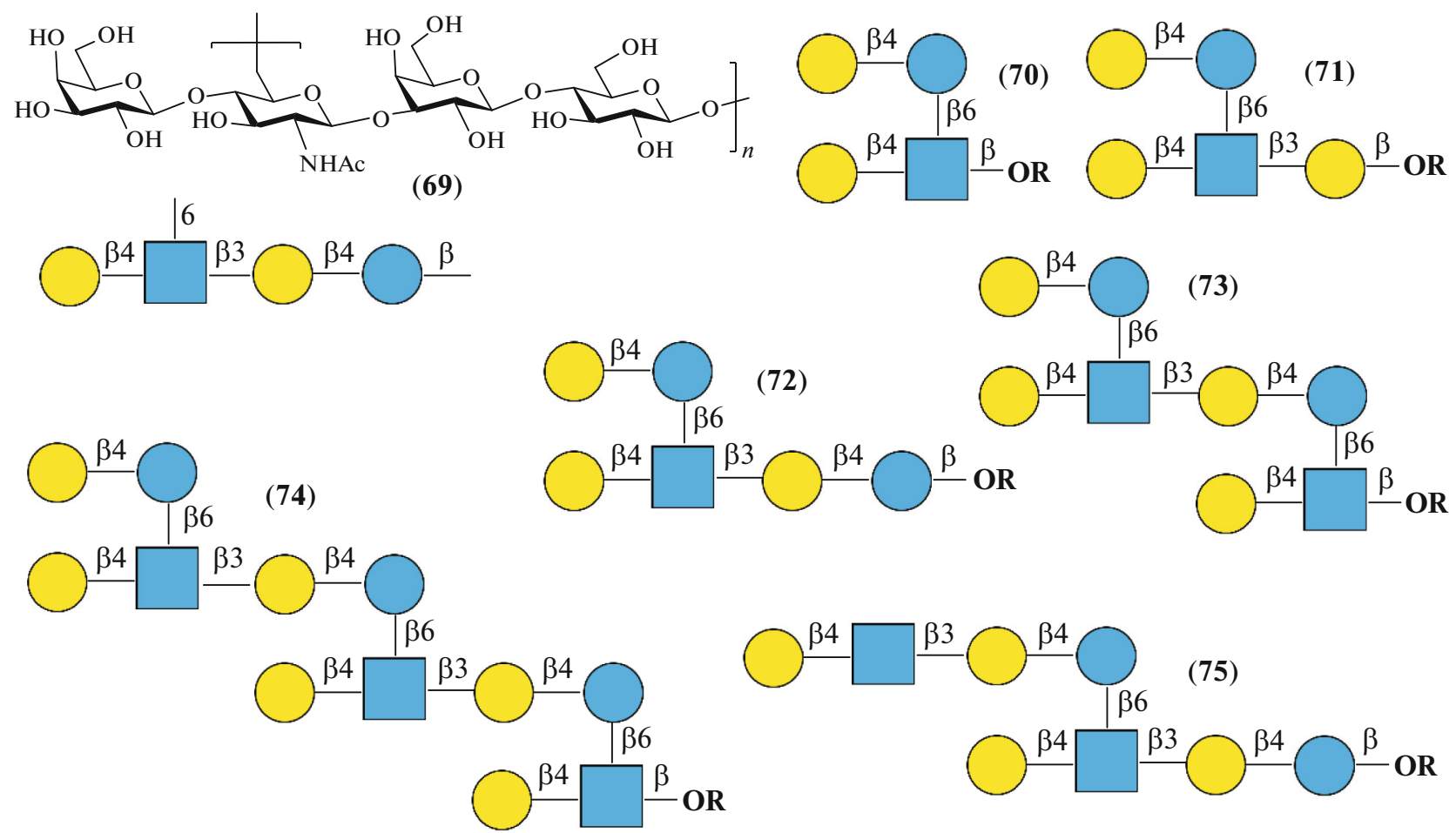

$$
\begin{aligned}
& \mathbf{a} \mathbf{R}=\mathrm{Sp}-\mathrm{NH}_{2} \\
& \mathbf{b} \mathbf{R}=\mathrm{Sp}-\mathrm{CRM} 197 \\
& \mathbf{c} \mathbf{R}=\mathrm{Sp}-\mathrm{BSA} \\
& \mathbf{d} \mathbf{R}=\mathrm{Sp}-\mathrm{SH}
\end{aligned}
$$

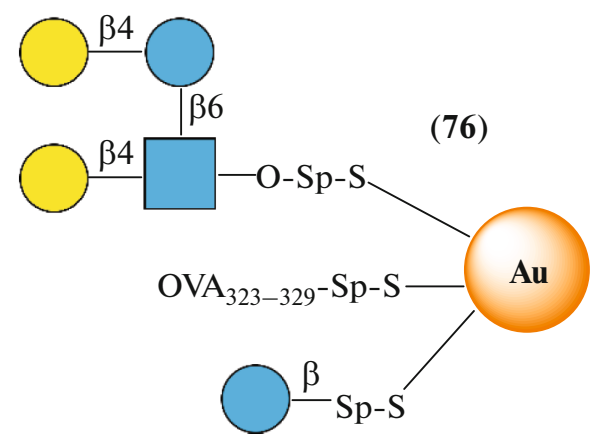

Fig. 11. Structure of the capsular polysaccharide of $S$. pneumoniae serotype 14 (repeating unit (69)), synthetic oligosaccharide derivatives (70a-75a), and conjugates (

the polysaccharide (69) that the presence of the $\beta$-Gal- $(1 \rightarrow 4)-\beta-$ Glc fragment at the nonreducing end of the oligosaccharide ligand is necessary for production of antibodies that bind to the native CP (69) [55]. In particular, the conjugates $\mathbf{( 7 0 b - 7 4 b )}$ (Fig. 11) induced formation of high titers of antibodies specific to $\mathrm{CP}(69)$ in the presence of various adjuvants (MPL and Quil-A) in mice, while phagocytic activity of the obtained antibodies was directly dependent on the titers of antibodies to CP of the serotype 14 (69). It was specifically shown that the sera containing no antibodies specific to the polysaccharide (69) did not show any phagocytic activity against the pneumococci of serotype 14. It was concluded based on the results of comparative experiments that the tetrasaccharide ligand in the conjugate (70b) contained epitopes necessary for induction of the protective antibodies and represented a minimal structural motif for production of the opsonizing antibodies against the repeating unit of the CP (69) [130]. If the antibodies to the conjugate (70b) would also exhibit protective effects in animal experiments, such conjugate could be considered as a promising component of the multi-valent pneumococcal vaccine corresponding to the serotype 14 .

In the studies investigating effect of the second immunization, mice were first injected with the conjugate (70b), and second immunization was performed either with the same glycoconjugate or with the unconjugated bacterial $\mathrm{CP}$ (69). On the 1st day after the second administration of the conjugated tetrasaccharide, the level of IL-5 in the blood serum of mice increased, and on the 7th day, high titers of the specific IgG antibodies appeared. No increase in the 
level of IL-5 or antibodies to CP was observed after immunization with the CP (69). Stimulation of splenocytes with the conjugate (70b) in the in vitro experiments induced production of IL-4 and IL-5, which was not observed during immunization with the unconjugated CP (69). However, stimulation of the splenocytes derived from the mice immunized twice with inactivated $S$. pneumoniae serotype 14 cells, induced production of higher levels of IFN $\gamma$ and IL-17 if the mice were immunized with the native bacterial $\mathrm{CP}$ than in the case of the mice that had booster immunization with the synthetic tetrasaccharide conjugate and the mice that were not immunized. This allowed to conclude that the memory cells are activated and a pronounced immunity to $S$. pneumoniae serotype 14 is formed after the second immunization with the conjugated tetrasaccharide (70b), while the repeated immunization with the conjugated bacterial $\mathrm{CP}$ does not lead to formation of the opsonizing antibodies, although it is involved in certain regulatory immunological mechanisms [131].

The authors of this review produced and investigated conjugates $(\mathbf{7 0 c}),(\mathbf{7 2 c})$, and $(\mathbf{7 5 c})[127,128]$. The ability of mice immune sera to conjugates of tetra(70c) and octasaccharide (75c) to induce opsonophagocytosis of the $S$. pneumoniae serotype 14 cells killed by heating was higher than the activity of antisera to the conjugated hexasaccharide (72c). Protective activity of the BSA glycoconjugates adsorbed on aluminum hydroxide was first demonstrated in the mouse model of septic pneumococcal infection with $S$. pneumoniae serotype 14 . Inoculation of nonimmunized mice with the pooled sera derived from mice immunized with the highest tested dose of each glycoconjugate did not reveal any differences in the passive protection of mice against infection depending on the glycoconjugate. It was shown that $\mathrm{IgG} 1$ antibodies to tetrasaccharide (70a) were formed in mice in response to vaccination with CRM197-CP $(69 b)$. Formation of large amounts of specific antibodies to tetrasaccharide (70a) and its protective effects confirm that the tetrasaccharide (70a) is a promising candidate for developing a conjugate vaccine against diseases caused by S. pneumoniae serotype 14 [127, 128].

The conjugate (72c) with synthetic hexasaccharide ligand was selected to evaluate the effect of glycoconjugates at the molecular and cellular levels. Immunization with the conjugate (72c) without adjuvant increased the number of TLR2-expressing cells and induced maturation of the dendritic cells $\left(\mathrm{CD} 11 \mathrm{c}^{+}\right.$, $\mathrm{CD}^{+} 0^{+}$, and $\mathrm{MHCII}^{+}$) that secreted $\mathrm{IL}-1 \beta, \mathrm{IL}-6$, and TNF $\alpha$ into the culture medium. The levels of IL-1 $\beta$, IL-10, IFN $\gamma$, and TNF $\alpha$ in the blood of mice increased within $24 \mathrm{~h}$ after single administration of the glycoconjugate (72c). On the 7th day, the number of $\mathrm{CD}^{+}$and $\mathrm{CD}^{+}{ }^{+}$-lymphocytes in spleen and of $\mathrm{B}$ lymphocytes increased. Fourteen days after the second immunization, the levels of $\mathrm{CD}^{+}$and $\mathrm{CD} 8^{+}$
T-lymphocytes were lower than in the control, while the number of B cells, NK cells, and MHCII-expressing cells remained increased.

Addition of aluminum hydroxide to the glycoconjugate (72c) stimulated production of GM-CSF, IL$1 \beta$, IL-5, IL-6, IL-10, IL-17, IFN $\gamma$, and TNF $\alpha$. Seven days after the second immunization with the glycoconjugate with adjuvant the titers of IgG1 antibodies to $S$. pneumoniae serotype $14 \mathrm{CP}$ were high. During this period, normal levels of $\mathrm{CD}^{+}{ }^{+} \mathrm{T}$ lymphocytes in spleen were maintained, while decrease in the number of $\mathrm{CD}^{+} \mathrm{T}$ lymphocytes and increase in the levels of B lymphocytes, NK cells, and cells expressing MHCII were observed. The level of IgG1 antibodies decreased by the 92nd day of observation. Booster immunization with the glycoconjugate (72c) adsorbed on aluminum hydroxide stimulated production of IgG1 antibodies to CP, which were detected over 97 days. Elucidation of the specific features of the effect of synthetic hexasaccharide conjugate (72c) on the stimulation of innate, cell-mediated immunity, and antibody response could facilitate optimization of the composition of pneumococcal glycoconjugate vaccine [129].

Gold nanoclusters have also been used as carriers in the development of synthetic pneumococcal vaccines. In particular, nanoparticles (76) (Fig. 11) were produced that carried a tetrasaccharide ligand representing repeating unit of the $\mathrm{CP}$ of pneumococcal serotype 14 (69) [132]. The tetrasaccharide (70d) containing terminal thiol group for nanoparticle functionalization was conjugated together with the T-cell stimulating peptide $\left(\mathrm{OVA}_{323-329}\right)$ and $\mathrm{D}$-glucose ligand to form hybrid $\sim 2-\mathrm{nm}$ nanoparticles (76). Immunological studies in mice showed that the glycocluster (76) induced formation of antibodies specific to the serotype 14 CP (69). Antisera obtained upon immunization of mice with the nanoparticles (76) were capable of opsonophagocytosis of pneumococci serotype 14, however, less efficiently than the sera from the mice immunized with the conjugate of bacterial CP (69) with CRM197.

\section{S. pneumoniae serotype $17 F$}

Capsular polysaccharide of the $S$. pneumoniae serotype 17F (77) (Fig. 12) is included only in the 23valent polysaccharide vaccines Pneumovax $23^{\circledR}$ and Pneumo $23^{\circledR}$. Its repeating unit contains seven monosaccharide residues and has a rather complex structure. As a result, the structure of the compound (77) was initially determined incorrectly. The oligosaccharide ligands $(\mathbf{7 8 a}-\mathbf{8 0 a})$ were synthesized on the basis of the erroneous structure of $\mathrm{CP}$ of the serotype $17 \mathrm{~F}$ [133] (Fig. 12). The corresponding conjugates (78b80b) were also obtained and used to immunize mice and rabbits. The conjugates of di- (78b) and trisaccharide (79b) induced formation of antibodies specific to 


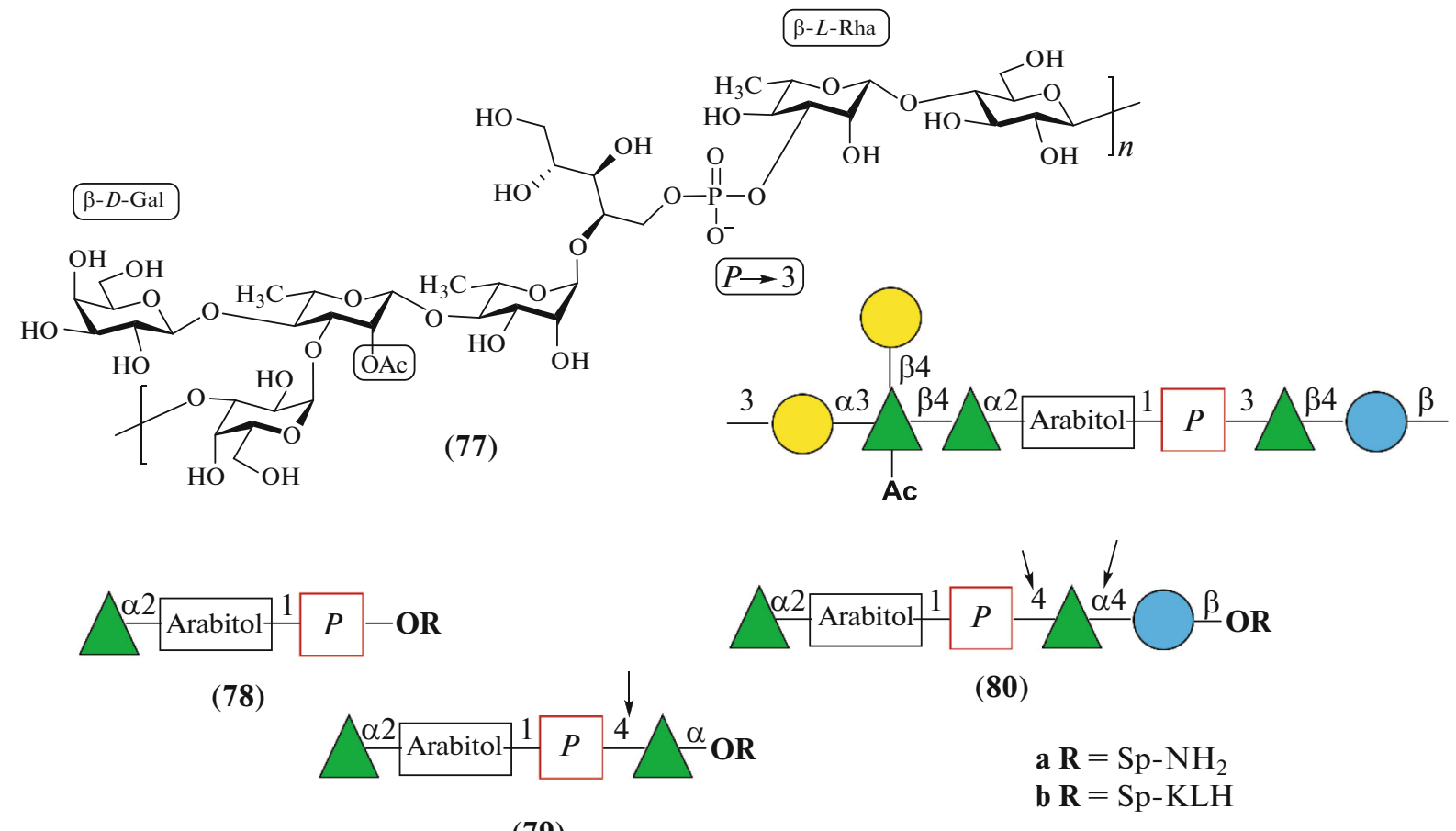

(79)

Fig. 12. Structure of the capsular polysaccharide of $S$. pneumoniae serotype 17F (repeating unit (77)), synthetic oligosaccharide derivatives (78a, 79a), and conjugates with KLH (series b).

the $\mathrm{CP}$ of serotype $17 \mathrm{~F}$ (77) in both animal species, and also protected mice from infection with the encapsulated $S$. pneumoniae serotype 17F strains in the experiments with active immunization. The tetrasaccharide conjugate (80b) was not able to induce CPspecific antibodies and also did not show protective effects. Later, when the structure of the CP of serotype $17 \mathrm{~F}$ (77) was clarified, it became clear that the structure of the tetrasaccharide ligand (80a) contained two errors (indicated by arrows in the diagram) compared to the correct chemical structure (77). The presence of one error in the trisaccharide ligand (79a) did not play any role. This led to conclusion that the disaccharide (78a) already contains a key protective epitope [134]. More detailed research is required to verify this assumption.

\section{S. pneumoniae serotype $19 F$}

$\mathrm{CP}$ of the $S$. pneumoniae serotype 19F (81) (Fig. 13) is included in all licensed pneumococcal vaccines. A glycoconjugate nanocluster (83) was designed that contained the trisaccharide ligand $(\mathbf{8 2 b})$ corresponding to the repeating unit of this $C P(\mathbf{8 1})$, along with the tetrasaccharide ligand (70d) (corresponding to the serotype 14) [135]. Immunization of mice with the glyconanoparticles (83) resulted in induction of antibodies specific to the CP of the serotype 14 (69). Furthermore, the antibody titers were higher than in the case of particles (76) containing only the ligand of the serotype 14. However, production of the antibodies specific to $\mathrm{CP}$ of the serotype $19 \mathrm{~F}$ was not observed. Research in this direction continues.

\section{S. pneumoniae serotype $23 F$}

The CP of the pneumococcus serotype 23F (83) (Fig. 14) has tetrasaccharide repeating unit in its structure and is included in the 23-valent pneumococcal polysaccharide vaccines Pneumovax $23^{\circledR}$ and Pneumo $23^{\circledR}$. The trisaccharide $(\mathbf{8 4 a})$ and tetrasaccharide $(\mathbf{8 5 a})$ (corresponding to the complete repeating unit) ligands, as well as their conjugates with the protein carrier KLH $(\mathbf{8 4 b}, \mathbf{8 5 b})$ were synthesized $[136,137]$ in attempts to identify optimal oligosaccharide ligand that could be used in the development of the corresponding vaccine candidate (Fig. 14). The KLH conjugate with the $\mathrm{CP}$ of serotype $23 \mathrm{~F}$ was also used in investigation of their immunogenicity.

The results of immunization of rabbits and mice showed significant differences in the immunogenicity of these conjugates. In particular, the conjugate with tetrasaccharide (85b) induced formation of antibodies specific to the $\mathrm{CP}$ of serotype $23 \mathrm{~F}(\mathbf{8 3})$ in rabbits, while the same conjugate turned out to be completely nonimmunogenic in mice [137]. Furthermore, the trisaccharide conjugate $(\mathbf{8 4 b})$ was found to be only weakly immunogenic in rabbits and did not induce formation of antibodies that bind to the bacterial $\mathrm{CP}$ (83). The antibodies induced in rabbits by the conju- 

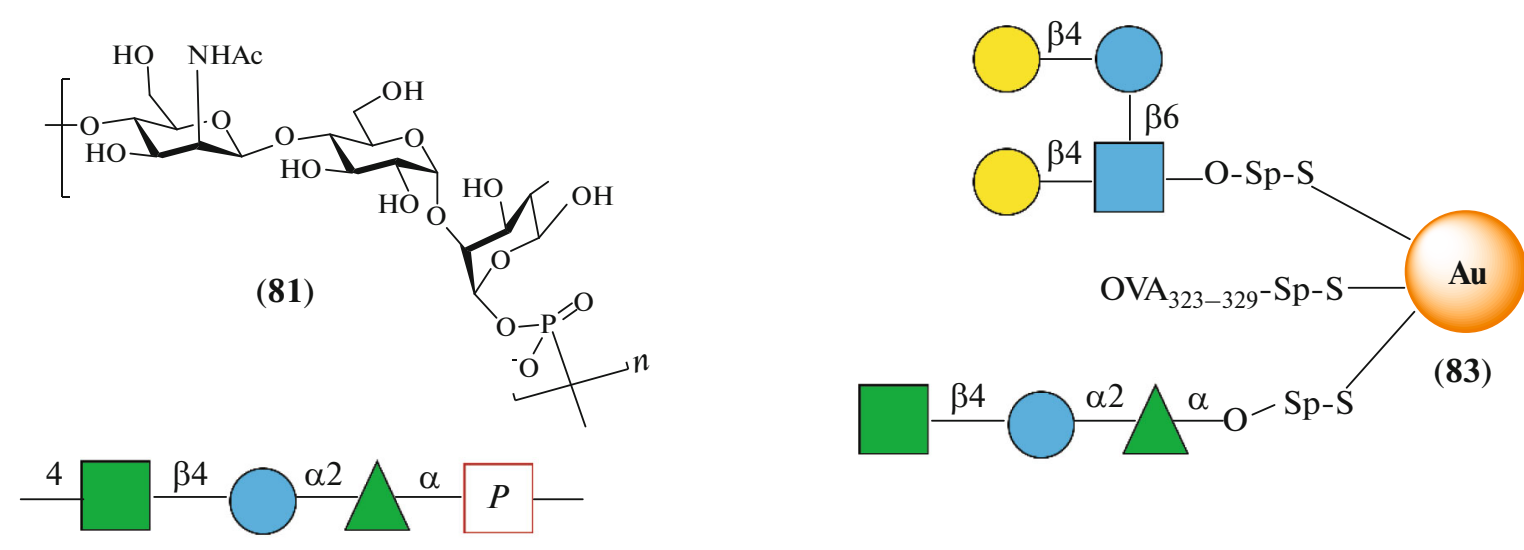

(82)

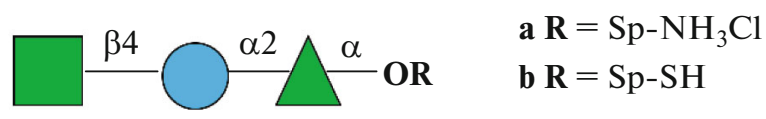

Fig. 13. Structure of the capsular polysaccharide of $S$. pneumoniae serotype 19F (repeating unit (81)), synthetic trisaccharide derivative with an aglycon spacer $(\mathbf{8 2 a}, \mathbf{8 2 b})$, and hybrid nanoparticles $\mathbf{( 8 3 )}$.
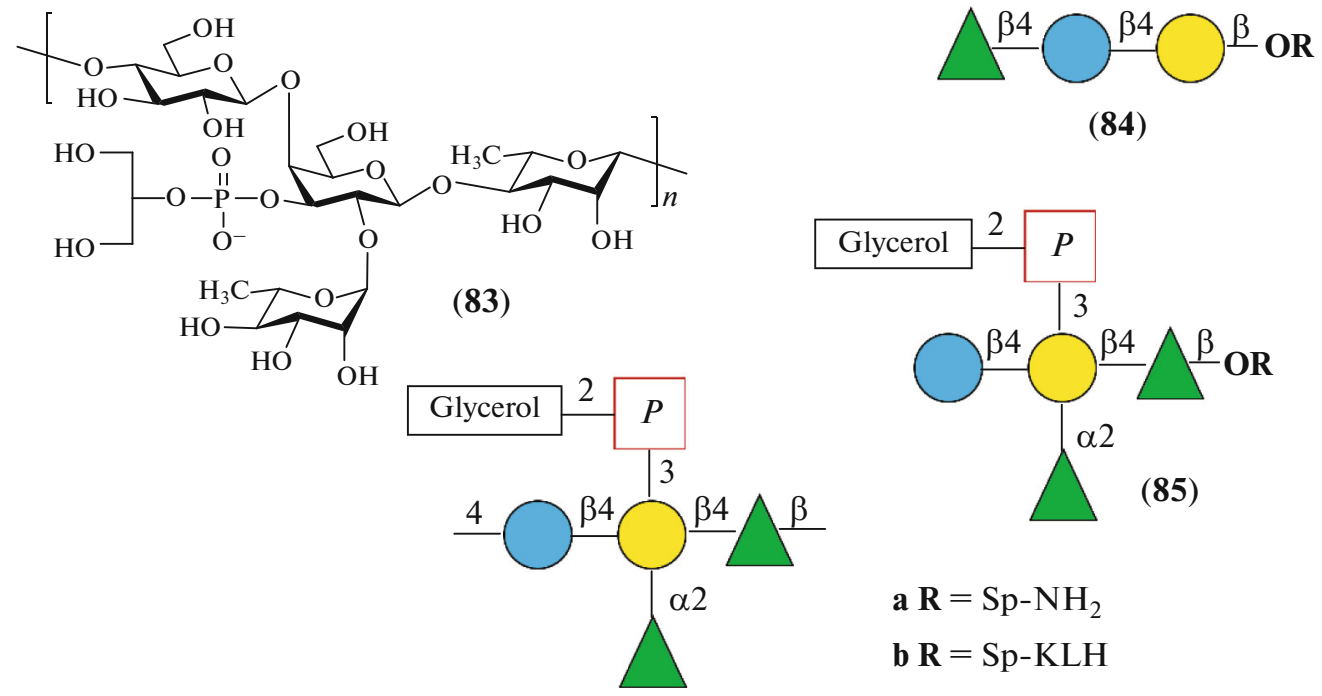

(84)

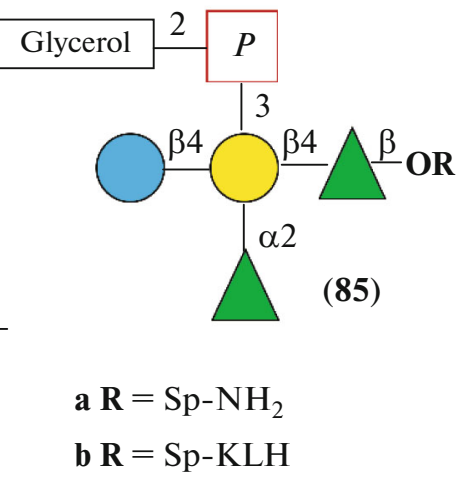

Fig. 14. Structure of the capsular polysaccharide of $S$. pneumoniae serotype $23 \mathrm{~F}$ (repeating unit (83)), synthetic oligosaccharide derivatives $(\mathbf{8 4 a}, \mathbf{8 5 a})$, and conjugates with KLH (series b).

gates of $\mathrm{CP}$ of serotype $23 \mathrm{~F}(\mathbf{8 3 b})$ and its complete repeating unit $\mathbf{( 8 5 b )}$ were shown to have the same epitope specificity in the cross-inhibition experiments, but differ in specificity from the human antibodies that were obtained in response to immunization with the polysaccharide (83) as a part of the commercial 23valent pneumococcal polysaccharide vaccine [138].

Antisera derived from humans immunized with the CP (83) contain high titers of antibodies that bind to the CP of serotype $23 \mathrm{~F} \mathrm{(83)}$; however, this interaction can be only slightly inhibited by the conjugates of synthetic oligosaccharides $(\mathbf{8 4 b})$ and $(\mathbf{8 5 b})$. At the same time, the considered human antiserum exhibits a five times higher opsonizing capacity in the in vitro tests than the rabbit antiserum to the polysaccharide conjugate $(\mathbf{8 3 b})$. In the same tests, the serum from rabbits immunized with the tetrasaccharide conjugate $\mathbf{( 8 5 b}$ ) was two times less active than the antiserum to the polysaccharide conjugate $\mathbf{( 8 3 b )}$. The antibodies induced by the trisaccharide conjugate $(\mathbf{8 4 b})$ did not induce opsonization of the $23 \mathrm{~F}$ serotype pneumococci, which was in agreement with the fact that the antiserum to the trisaccharide conjugate $(\mathbf{8 4 b})$ did not bind to the native CP of the serotype $23 \mathrm{~F}$ (83) [138].

The results of these studies clearly show that immunogenicity, as well as epitope specificity of the 


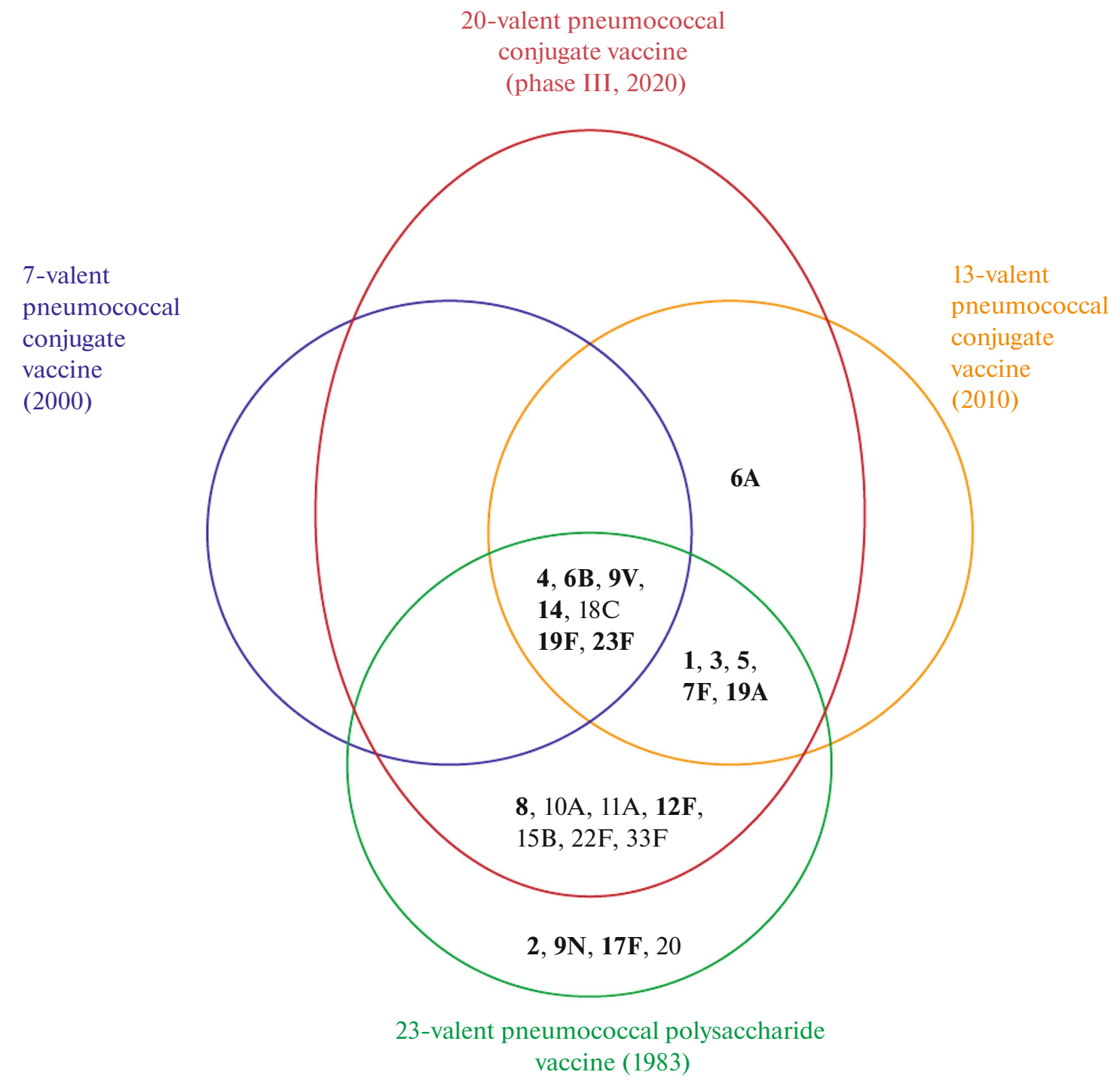

Fig. 15. Distribution of serotypes in pneumococcal vaccines. S. pneumoniae serotypes considered in this review, which are studied using synthetic oligosaccharide fragments of corresponding capsular polysaccharides, are highlighted in bold.

immune response in different laboratory animals and humans, can differ significantly. The authors suggested that in contrast to the rabbit antibodies, which recognized smaller epitopes present in the short oligosaccharide ligands, the human IgGs were capable of recognizing larger epitopes (including conformational epitopes in the large carbohydrate antigens). Therefore, detailed study of the immune response in humans is necessary to evaluate vaccine effectiveness [138].

\section{CONCLUSIONS}

The serotypes of $S$. pneumoniae considered in the review are widespread in all geographic regions and are among the pneumococcal serotypes that most often cause diseases in children and adults. Capsular polysaccharides of almost all these $S$. pneumoniae serotypes are included in the licensed pneumococcal polysaccharide and conjugate vaccines. However, despite the effectiveness of the currently used vaccines, constant monitoring of the distribution of various pneumococcal serotypes and timely introduction of the vaccine preparations containing antigens for the most relevant serotypes is required.

The development of pneumococcal polysaccharide conjugate vaccines is an ongoing process and Pfizer is preparing for licensing the 20-valent vaccine (Prevnar $20^{\circledR}$, in Phase III clinical trials) that contains seven additional serotypes of polysaccharide conjugates compared to the currently used Prevnar $13^{\circledR}$ vaccine. Distribution of the pneumococcal serotypes in the composition of 7-, 13-, 20-, and 23-valent vaccine preparations is summarized in Fig. 15. 
The use of polysaccharides obtained by biotechnological methods for production of the conjugate vaccines is still associated with technical difficulties. Among the pneumococcal serotypes considered in this review, many CPs contain labile substituents or functional groups that are modified upon isolation or during conjugation with protein carriers, which leads to distortion of the active epitopes and decrease in immunogenicity of the corresponding vaccine components. Therefore, work is actively underway on the synthesis of CP fragments of the most epidemiologically relevant serotypes as well as the search for epitopes responsible for production of protective antibodies. Extensive research in this area has made it possible to create certain algorithms for the efficient selection of the most active carbohydrate ligands. Modern methods allow automated screening of carbohydrate ligands using on-chip carbohydrate arrays [54, 59, 62] and other carriers [139-145] to study epitope specificity of the tested antibodies. New efficient methods for synthesis of the most complex types of oligosaccharides have also been developed (see, for example, [146-149]), including the automated synthesis of oligosaccharides $[150,151]$, which significantly simplifies preparation of extended libraries of the carbohydrate ligands.

The problems arising during development of the synthetic carbohydrate vaccines are in many ways similar to the challenges recognized in the development of conjugate vaccines based on bacterial polysaccharides. These include the search for optimal conjugation method and evaluation of the effect of the linker on immunogenicity of the conjugate, correct choice of the adjuvant, as well as the observed differences in the immune responses to the administered vaccines between various laboratory animals and humans. Nevertheless, in most cases it is possible to find the necessary conditions for designing highly immunogenic conjugates of synthetic oligosaccharides that induce formation of the protective antibodies.

The immunologically-active oligosaccharides elicit production of antibodies to capsular polysaccharides and enhance complement-dependent opsonophagocytosis. Some oligosaccharide conjugates produce even stronger antibody response than the conjugates of bacterial CPs of the individual serotypes. This important fact allows suggesting that it is possible to replace natural CPs of such serotypes with the synthetic oligosaccharides for creation of a polyvalent synthetic pneumococcal vaccine. One successful example of the combined use of the 13-valent conjugate vaccine and the conjugate of a synthetic oligosaccharide corresponding to the fragment of the capsular polysaccharide of $S$. pneumoniae serotype 8 is already known [119]. Nevertheless, recent advances in the oligosaccharide synthesis allow producing almost any oligosaccharide derivatives, which could facilitate development of a pneumococcal vaccine based only on synthetic oligosaccharide ligands in the nearest future. It is also important that the techniques involved in processing of such derivatives are in better compliance with the good manufacturing practices (GMP) in pharmaceutical industry at the stage of production of both vaccine ligands and their conjugates with carrier proteins or other functional components, including glycolipid adjuvants [152].

\section{FUNDING}

The work was financially supported by the Russian Science Foundation (project no. 19-73-30017).

\section{COMPLIANCE WITH ETHICAL STANDARDS}

The article contains no description of studies with human participants or animals performed by any of the authors.

\section{Conflict of Interests}

The authors declare no conflicts of interests in financial or any other sphere.

\section{REFERENCES}

1. Henrichsen, J., J. Clin. Microbiol., 1995, vol. 33, pp. 2759-2762.

https://doi.org/10.1128/JCM.33.10.2759-2762.1995

2. Lund, E. and Henrichsen, J., in Methods in Microbiology, Bergan, T. and Norris, J.R., Eds., London, United Kingdom: Academic, 1978, pp. 241-262.

3. Calix, J.J. and Nahm, M.H., J. Infect. Dis., 2010, vol. 202 , pp. $29-38$. https://doi.org/10.1086/653123

4. De Velasco, E., Verheul, A.F., Verhoef, J., and Snippe, H., Microbiol. Rev., 1995, vol. 59, pp. 591-603.

5. Rijkers, G.T., Sanders, L.A., and Zegers, B.J., Immunodeficiency, 1993, vol. 5, pp. 1-21.

6. Hausdorff, W.P., Bryant, J., Paradiso, P.R., and Siber, G.R., Clin. Infect. Dis., 2000, vol. 30, pp. 100-121. https://doi.org/10.1086/313608

7. Hausdorff, W.P., Bryant, J., Kloek, C., Paradiso, P.R., and Siber, G.R., Clin. Infect. Dis., 2000, vol. 30, pp. $122-140$. https://doi.org/10.1086/313609

8. Hausdorff, W.P., Yothers, G., Dagan, R., Kilpi, T., Pelton, S.I., Cohen, R., Jacobs, M.R., Kaplan, S.L., Levy, C., Lopez, E.L., Mason, E.O., Jr., Syriopoulou, V., Wynne, B., and Bryant, J., Pediatr. Infect. Dis. J., 2002, vol. 21, pp. 1008-1016.

https://doi.org/10.1097/00006454-200211000-00007

9. Hausdorff, W.P., Eur. J. Pediatr., 2002, vol. 161, suppl. 2, pp. S135-S139. https://doi.org/10.1007/s00431-002-1066-X

10. Joffe, M.D. and Alpern, E.R., Pediatr. Emerg. Care, 2010, vol. 6, pp. 448-454. https://doi.org/10.1097/PEC.0b013e3181e15e36

11. Johnson, H.L., Deloria-Knoll, M., Levine, O.S., Stoszek, S.K., Freimanis, HanceL., Reithinger, R., 
Muenz, L.R., and O'Brien, K.L., PLoS Med., 2010, vol. 7 , no. 10 , article e 1000348 .

https://doi.org/10.1371/journal.pmed.1000348

12. Athlin, S., Kaltoft, M., Slotved, H.C., Herrmann, B., Holmberg, H., Bossen Konradsen, H., and Stralina, K., Clin. Vaccine Immunol., 2014, vol. 21, pp. 1541-1549. https://doi.org/10.1128/CVI.00259-14

13. Littorin, N., Udden, F., Ahl, J., Resman, F., Slotved, H.-C., Athlin, S., and Riesbeck, K., Front. Microbiol., 2018, vol. 9, p. 2746. https://doi.org/10.3389/fmicb.2018.02746

14. Hyams, C., Yuste, J., Bax, K., Camberlein, E., Weiser, J.N., and Brown, J.S., Infect. Immun., 2010, vol. 78, pp. 716-725.

https://doi.org/10.1128/IAI.01056-09

15. Melin, M., Trzciński, K., Antonio, M., Meri, S., Adegbola, R., Kaijalainen, T., Käyhty, H., and Väkeväinen, M., Infect. Immun., 2010, vol. 78, pp. 52525261.

https://doi.org/10.1128/iai.00739-10

16. Melin, M., Jarva, H., Siira, L., Meri, S., Kayhty, H., and Vakevainen, M., Infect. Immun., 2009, vol. 77, pp. 676-684.

https://doi.org/10.1128/IAI.01186-08

17. Weinberger, D.M., Harboe, Z.B., Sanders, E.A., Ndiritu, M., Klugman, K.P., Rückinger, S., Dagan, R., Adegbola, R., Cutts, F., Johnson, H.L., O'Brien, K.L., Scott, J.A., and Lipsitch, M., Clin. Infect. Dis., 2010, vol. 51, pp. 692-699.

https://doi.org/10.1086/655828

18. Pneumococcal conjugate vaccine for childhood immunization, WHO position paper, Weekly Epidemiol. Rec., 2007, vol. 82, pp. 93-104.

19. Pneumococcal vaccines, WHO position paper, Weekly Epidemiol. Rec., 2012, vol. 87, pp. 129-144.

20. Kozlov, R.S., Sci. Pract. J. Interreg. Assoc. Clin. Microbiol. Antimicrob. Chemother., 2010, p. 25.

21. Kozlov, R.S., Chagaryan, A.N., Kozlova, L.V., and Muraviev, A.A., Klin. Mikrobiol. Antimikrob. Khimioter., 2011, vol. 13, pp. 177-187.

22. Mironov, K.O., Platonov, A.E., and Kozlov, R.S., Klin. Mikrobiol. Antimikrob. Khimioter., 2011, vol. 13, pp. 104-113.

23. Murav'ev, A.A., Chagaryan, A.N., Bratus', E.V., Pertseva, T.A., Karpov, I.A., and Kachanko, E.F., Klin. Mikrobiol. Antimikrob. Khimioter, 2013, vol. 15, pp. $147-158$.

24. Alexandre, C., Dubos, F., Courouble, C., Pruvost, I., Varon, E., and Martinot, A., Acta Paediatr., 2010, vol. 99, pp. 1686-1690.

https://doi.org/10.1111/j.1651-2227.2010.01914.x

25. Jamal, F., Pit, S., Isahak, I., Abdullah, N., Zainal, Z., Abdullah, R., and Henrichsen, J., Southeast Asian J. Trop. Med. Public Health, 1987, vol. 18, pp. 79-84.

26. Lin, T.Y., Shah, N.K., Brooks, D., and Garcia, C.S., Vaccine, 2010, vol. 48, pp. 7589-7605.

https://doi.org/10.1016/j.vaccine.2010.07.053

27. McIntosh, E.D., Fritzell, B., and Fletcher, M.A., Epidemiol. Infect., 2007, vol. 135, no. 4, pp. 644-656. https://doi.org/10.1017/S0950268806007199
28. Rusen, I.D. and Fraser-Poberts, M.D., Pediatr. Infect. Dis., 1997, vol. 16, pp. 656-662. https://doi.org/10.1097/00006454-199707000-00007

29. Jauneikaitea, E., Jefferies, J.M., Hibberdb, M.L., and Clarkea, S.C., Vaccine, 2012, vol. 30, pp. 3503-3514. https://doi.org/10.1016/j.vaccine.2012.03.066

30. Jansen, W.T. and Snippe, H., Indian J. Med. Res., 2004, vol. 119, suppl., pp. 7-12.

31. Butler, J.C., Microb. Drug Resist., 1997, vol. 3, pp. $125-129$. https://doi.org/10.1089/mdr.1997.3.125

32. CDC, Morb. Mortal. Wkly. Rep., 1997, vol. 46, no. RR-08, pp. 1-24.

33. CDC, Morb. Mortal. Wkly. Rep., 2008, vol. 57, pp. 1148-1151.

34. Inostroza, J., Vinet, A.M., Retamal, G., Lorca Ossa, G., Facklam, R.R., and Sorensen, R.U., Clin. Diagn. Lab. Immunol., 2001, vol. 8, pp. 556-559. https://doi.org/10.1128/CDLI.8.3.556-559.2001

35. Akata, K., Chang, B., Yatera, K., Kawanami, T., Yamasaki, K., Naito, K., Noguchi, S., Ishimoto, H., and Mukae, H., J. Infect. Chemother, 2015, vol. 21, pp. 723-728. https://doi.org/10.1016/j.jiac.2015.07.002

36. Chiba, N., Jpn. J. Chemother., 2011, vol. 59, pp. 561572.

37. Kuroki, T., Ishida, M., Suzuki, M., Furukawa, I., Ohya, H., Watanabe, Y., Konnai, M., Aihara, Y., Chang, B., Ariyoshi, K., Oishi, K., Ohnishi, M., and Morimoto, K., Am. Geriatr. Soc., 2014, vol. 62, pp. 1197-1198. https://doi.org/10.1111/jgs.12863

38. Al-Jardani, A., Al Rashdi, A., Al Jaaidi, A., Al Balushi, M., Al Mahruqi, S., Al-Abri, S., Al-Maani, A., and Kumar, R., Int. J. Infect. Dis., 2019, vol. 85, pp. 135140. https://doi.org/10.1016/j.ijid.2019.05.027

39. Lee, S., Lee, K., Kang, Y., and Bae, S., Microb. Drug Resist., 2010, vol. 16, pp. 135-142. https://doi.org/10.1089/mdr.2009.0114

40. Coffey, T., Derron, S., Daniels, M., Garcia-Leoni, M.E., Cercenado, E., Bouza, E., Fenoll, A., and Spratt, B.G., Microbiology, 1996, vol. 142, pp. 2742-2757. https://doi.org/10.1099/13500872-142-10-2747

41. España, P.P., Uranga, A., Ruiz, L.A., Quintana, J.M., Bilbao, A., Aramburu, A., Serrano, L., Ayarza, R., Martinez, A.P., and Zalacain, R., Vaccine, 2019, vol. 37, pp. 3840-3848. https://doi.org/10.1016/j.vaccine.2019.05.052

42. Reinter, R.R., Kaufhold, A., Kuhnemund, O., and Luttichen, R., Int. J. Med. Microbiol. Virol. Parasitol. Infect. Dis., 1994, vol. 281, pp. 481-490.

43. Tatochenko, V.K., Katosova, L.K., and Ulanova, M.A., J. Microbiol. Epidemiol. Immunobiol., 1994, pp. 3-10.

44. Beloshitsky, G.V. and Koroleva, I.S., Epidemiol. Vaktsinoprofilakt., 2014, vol. 1, pp. 90-97.

45. Douglas, R.M., Paton, J.C., Duncan, S.J., and Hansman, D.J., J. Infect. Dis., 1983, vol. 148, pp. 131-137. https://doi.org/10.1093/infdis/148.1.131

46. Thompson, A., Lamberth, E., Severs, J., Scully, I., Tarabar, S., Ginis, J., Jansen, K.U., Gruber, W.C., 
Scott, D.A., and Watson, W., Vaccine, 2019, vol. 37, pp. 6201-6207.

https://doi.org/10.1016/j.vaccine.2019.08.048

47. Nurkka, A., Joensuu, J., Henckaerts, I., Peeters, P., Poolman, J., Kilpi, T., and Kayhty, H.M., Pediatr. Infect. Dis. J., 2004, vol. 11, pp. 1008-1014. https://doi.org/10.1097/01.inf.0000143640.03214.18

48. Prymula, R., Peeters, P., Chrobok, V., Kriz, P., Novakova, E., Kaliskova, E., Kohl, I., Lommel, P., Poolman, J., Prieels, J.-P., and Schuerman, L., Lancet, 2006, vol. 367 , pp. $740-748$. https://doi.org/10.1016/S0140-6736(06)68304-9

49. Schuerman, L., Prymula, R., Chrobok, V., Dieussaert, I., and Poolman, J., Vaccine, 2007, vol. 25, pp. 19531961. https://doi.org/10.1016/j.vaccine.2006.12.007

50. Schuerman, L., Prymula, R., Henckaerts, I., and Poolman, J., Vaccine, 2007, vol. 25, pp. 1962-1968. https://doi.org/10.1016/j.vaccine.2006.12.008

51. Shiramoto, M., Hanada, R., Juergens, C., Shoji, Y., Yoshida, M., Ballan, B., Cooper, D., Gruber, W.C., Scott, D.A., and Schmoele-Thoma, B., Hum. Vaccine Immunother., 2015, vol. 11, pp. 2198-2206. https://doi.org/10.1080/21645515.2015.1030550

52. Simonsen, V., Brandão, A.P., Brandileone, M.C.C., Yara, T.I., Di Fabio, J.L., Lopes, M.H., and Jacob, FilhoW., Braz. J. Med. Biol. Res., 2005, vol. 38, pp. 251-260.

https://doi.org/10.1590/s0100-879x2005000200014

53. Andrews, N.J., Waight, P.A., Burbidge, P., Pearce, E., Roalfe, L., Zancolli, M., Slack, M., Ladhani, S.N., Miller, E., and Goldblatt, D., Lancet Infect. Dis., 2014, vol. 14, pp. 839-846. https://doi.org/10.1016/S1473-3099(14)70822-9

54. Schumann, B., Anish, C., Pereira, C.L., and Seeberger, P.H., Biotherapeutics, chapter 3: Carbohydrate Vaccines, Jones, L. and McKnight, A.J., Eds., Royal Society of Chemistry, 2013, pp. 68-104.

55. Gening, M.L., Kurbatova, E.A., Tsvetkov, Y.E., and Nifantiev, N.E., Russ. Chem. Rev., 2015, vol. 84, pp. $1100-1113$. https://doi.org/10.1070/RCR4574

56. Yu, X.H., Sun, Y., Frasch, C., Concepcion, N., and Nahm, M.H., Clin. Diagn. Lab. Immunol., 1999, vol. 6, pp. 519-524.

57. van Dam, J.E., Fleer, A., and Snippe, H., Antonie van Leeuwenhoek, 1990, vol. 58, pp. 1-47. https://doi.org/10.1007/BF02388078

58. Kamerling, J.P., Pneumococcal polysaccharides: A chemical view, in Streptococcus pneumoniae, Molecular Biology and Mechanisms of Disease, Tomasz, A., Ed., New York: Mary Ann Liebert, 1999, pp. 81-114.

59. Kaplonek, P., Khan, N., Reppe, K., Schumann, B., Emmadi, M., Lisboa, M.P., Xu, F.-F., Calow, A.D.J., Parameswarappa, S.G., Witzenrath, M., Pereira, C.L., and Seeberger, P.H., Proc. Natl. Acad. Sci. U. S. A., 2018, vol. 115, pp. 13353-13358.

https://doi.org/10.1073/pnas.1811862115

60. Jansen, W.T., Hogenboom, S., Thijssen, M.J., Kamerling, J.P., Vliegenthart, J.F., Verhoef, J., Snippe, H., and Verheul, A.F.M., Infect. Immun., 2001, vol. 69, pp. $787-793$.

https://doi.org/10.1128/IAI.69.2.787-793.2001

61. Benaissa-Trouw, B., Lefeber, D.J., Kamerling, J.P., Vliegenthart, J.F.G., Kraaijeveld, K., and Snippe, H., Infect. Immun., 2001, vol. 69, pp. 4698-4701. https://doi.org/10.1128/IAI.69.7.4698-4701.2001

62. Parameswarappa, S.G., Reppe, K., Geissner, A., Menova, P., Govindan, S., Calow, A.D.J., Wahlbrink, A., Weishaupt, M.W., Monnanda, B.P., Bell, R.L., Pirofski, L-A., Suttorp, N., Sander, L.E., Witzenrath, M., Pereira, C.L., Anish, C., and Seeberger, P.H., Cell Chem. Biol., 2016, vol. 23, pp. 1407-1416. https://doi.org/10.1016/j.chembiol.2016.09.016

63. Astronomo, R.D. and Burton, D.R., Nat. Rev. Drug Discov., 2010, vol. 9, pp. 308-324. https://doi.org/10.1038/nrd3012

64. Schumann, B., Reppe, K., Kaplonek, P., Wahlbrink, A., Anish, C., Witzenrath, M., Pereira, C.L., and Seeberger, P.H., ACS Cent. Sci., 2018, vol. 4, pp. 357-361. https://doi.org/10.1021/acscentsci.7b00504

65. Gessner, B.D., Mueller, J.E., and Yaro, S., BMC Infect. Dis., 2010, vol. 10, article 22. https://doi.org/10.1186/1471-2334-10-22

66. Poolman, J., Frasch, C., Nurkka, A., Ka?yhty, H., Biemans, R., and Schuerman, L., Clin. Vaccine Immunol., 2011, vol. 18, pp. 327-336. https://doi.org/10.1128/CVI.00402-10

67. Schumann, B., Pragani, R., Anish, C., Pereira, C.L., and Seeberger, P.H., Chem. Sci., 2014, vol. 5, pp. 1992-2002. https://doi.org/10.1039/C3SC53362J

68. Wu, X., Cui, L., Lipinski, T., and Bundle, D.R., Chem.-Eur. J., 2010, vol. 16, pp. 3476-3488. https://doi.org/10.1002/chem.201090046

69. Christina, A.E., Bos, L.J., Overkleeft, H.S., van der Marel, G.A., and Codee, J.D.C., Org. Chem., 2011, vol. 76, pp. 1692-1706. https://doi.org/10.1021/jo102363d

70. Pfister, H.B. and Mulard, L.A., Org. Lett., 2014, vol. 16, pp. 4892-4895. https://doi.org/10.1021/ol502395k

71. Emmadi, M. and Kulkarni, S.S., Nat. Prod. Rep., 2014, vol. 31, pp. 870-879.

https://doi.org/10.1039/C4NP00003J

72. Goldblatt, D., Plikaytis, B.D., Akkoyunlu, M., Antonello, J., Ashton, L., Blake, M., Burton, R., Care, R., Durant, N., Feavers, I., Fernsten, P., Fievet, F., Giardina, P., Jansen, K., Katz, L., Kierstead, L., Lee, L., Lin, J., Maisonneuve, J., Nahm, M.H., Raab, J., Romero-Steiner, S., Rose, C., Schmidt, D., Stapleton, J., and Carlone, G.M., Clin. Vaccine Immunol., 2011, vol. 18, pp. 1728-1736. https://doi.org/10.1128/CVI.05252-11

73. Emmadi, M., Khan, N., Lykke, L., Reppe, K., Parameswarappa, S.G., Lisboa, M.P., Wienhold, S.M., Witzenrath, M., Pereira, C.L., and Seeberger, P.H., J. Am. Chem. Soc., 2017, vol. 139, pp. 14783-14791. https://doi.org/10.1021/jacs.7b07836

74. Gruber, W.C., Scott, D.A., and Emini, E.A., Ann. N.Y. Acad. Sci., 2012, vol. 1263, pp. 15-26. https://doi.org/10.1111/j.1749-6632.2012.06673.x 
75. Choi, E.H., Zhang, F., Lu, Y.-J., and Malleya, R., Clin. Vaccine Immunol., 2016, vol. 23, pp. 162-167. https://doi.org/10.1128/CVI.00591-15

76. Cartee, R.T., Forsee, W.T., Schutzbach, J.S., and Yother, J., J. Biol. Chem., 2000, vol. 275, pp. 3907-3914. https://doi.org/10.1074/jbc.275.6.3907

77. Dillard, J.P., Vandersea, M.W., and Yother, J., J. Exp. Med., 1995, vol. 181, pp. 973-983. https://doi.org/10.1084/jem.181.3.973

78. Guidolin, A., Morona, J.K., Morona, R., Hansman, D., and Paton, J.C., Infect. Immun., 1994, vol. 62, pp. 5384-5396. https://doi.org/10.1128/IAI.62.12.5384-5396.1994

79. Kolkman, M.A., Wakarchuk, W., Nuijten, P.J., and van der Zeijst, B.A., Mol. Microbiol., 1997, vol. 26, pp. 197-208. https://doi.org/10.1046/j.1365-2958.1997.5791940.x

80. Arrecubieta, C., Lopez, R., and Garcia, E., J. Exp. Med., 1996, vol. 184, pp. 449-455. https://doi.org/10.1084/jem.184.2.449

81. Moore, M.R., Link-Gelles, R., Schaffner, W., Lynfield, R., Lexau, C., Bennett, N.M., Petit, S., Zansky, S.M., Harrison, L.H., Reingold, A., Miller, L., Scherzinger, K., Thomas, A., Farley, M.M., Zell, E.R., Taylor, T.H.Jr., Pondo, T., Rodgers, L., McGee, L., Beall, B., Jorgensen, J.H., and Whitney, C.G., Lancet Infect. Dis., 2015, vol. 15, pp. 301-309.

https://doi.org/10.1016/S1473-3099(14)71081-3

82. Cartee, R.T., Forsee, W.T., and Yother, J., J. Bacteriol., 2005, vol. 187, pp. 4470-4479.

https://doi.org/10.1128/JB.187.13.4470-4479.2005

83. Goebel, W.F., J. Exp. Med., 1940, vol. 72, pp. 33-48. https://doi.org/10.1084/jem.72.1.33

84. Pichichero, M.E., Porcelli, S., Treanor, J., and Anderson, P., Vaccine, 1998, vol. 16, pp. 83-89. https://doi.org/10.1016/s0264-410x(97)00146-1

85. Laferriere, C.A., Sood, R.K., de Muys, J.M., Michon, F., and Jennings, H.J., Vaccine, 1997, vol. 15, pp. 179186. https://doi.org/10.1016/S0264-410X(96)00148-X

86. Lindblad, E.B., Immunol. Cell Biol., 2004, vol. 82, pp. 497-505.

https://doi.org/10.1111/j.0818-9641.2004.01286.x

87. Reppe, K., Tschernig, T., Lührmann, A., van Laak, V., Grote, K., Zemlin, M.V., Gutbier, B., Müller, H.C., Kursar, M., Schutte, H., Rosseau, S., Pabst, R., Suttorp, N., and Witzenrath, M., Am. J. Respir. Cell Mol. Biol., 2009, vol. 40, pp. 474-481.

https://doi.org/10.1165/rcmb.2008-00710C

88. Witzenrath, M., Pache, F., Lorenz, D., Koppe, U., Gutbier, B., Tabeling, C., Reppe, K., Meixenberger, K., Dorhoi, A., Ma, J., Holmes, A., Trendelenburg, G., Heimesaat, M.M., Bereswill, S., van der Linden, M., Tschopp, J., Mitchell, T.J., Suttorp, N., and Opitz, B., J. Immunol., 2011, vol. 187, pp. 434-440. https://doi.org/10.4049/jimmunol.1003143

89. Xiong, C., Feng, S., Qiao, Y., Guo, Z., and Gu, G., Chem.-Eur. J., 2018, vol. 24, pp. 8205-8216. https://doi.org/10.1002/chem.201800754

90. Pereira, C.L., Geissner, A., Anish, C., and Seeberger, P.H., Angew. Chem., Int. Ed. Engl., 2015, vol. 54, pp. $10016-10019$.

https://doi.org/10.1002/anie.201504847

91. Geissner, A., Pereira, C.L., Leddermann, M., Anish, C., and Seeberger, P.H., ACS Chem. Biol., 2016, vol. 11, pp. 335-344.

https://doi.org/10.1021/acschembio.5b00768

92. Ginsburg, A.S. and Alderson, M.R., Drugs Today (Barc.), 2011, vol. 47, pp. 207-214.

https://doi.org/10.1358/dot.2011.47.3.1556471

93. Ravenscroft, N., Costantino, P., Talaga, P., Rodriguez, R., and Egan, W., Vaccine Analysis: Strategies, Principles, and Control (eBook), Springer, 2015, pp. 301-381.

94. Cipollo, J.F., Review of Manufacturing ProcessPrevnar13 (Pneumococcal 13-Valent Conjugate Vaccine (Diphteria CRM197 Protein)), Food Agric Org, Rome, 2009. www.fda.gov/downloads/BiologicsBloodVaccines/Vaccines/ApprovedProducts/UCM570727.zip. Accessed September 22, 2017.

95. Lisboa, M.P., Khan, N., Martin, C., Xu, F.-F., Reppe, K., Geissner, A., Govindan, S., Witzenrath, M., Pereira, C.L., and Seeberger, P.H., Proc. Natl. Acad. Sci. U. S. A., 2017, vol. 114, pp. 11063-11068. https://doi.org/10.1073/pnas.1706875114

96. Sucher, A.J., Chahine, E.B., Nelson, M., and Sucher, B.J., Ann. Pharmacother., 2011, vol. 45, pp. 1516-1524. https://doi.org/10.1345/aph.1Q347

97. Khatun, F., Stephenson, R.J., and Toth, I., Chemistry, 2017, vol. 23, pp. 4233-4254.

https://doi.org/10.1002/chem.201603599

98. Dagan, R., Poolman, J., and Siegrist, C.-A., Vaccine, 2010, vol. 28, pp. 5513-5523.

https://doi.org/10.1016/j.vaccine.2010.06.026

99. Gray, B.M., Converse, G.M., and Dillon, H.C., Jr., J. Infect. Dis., vol. 140, no. is. 1979, pp. 979-983. https://doi.org/10.1093/infdis/140.6.979

100. Siber, G.R., Science, 1994, vol. 265, pp. 1385-1387. https://doi.org/10.1126/science. 8073278

101. Breiman, R.F., Butler, J.C., Tenover, F.C., Elliott, J.A., and Facklam, R.R., JAMA, 1994, vol. 271, pp. 18311835.

102. Novak, R., Henriques, B., Charpentier, E., Normark, S., and Tuomanen, E., Nature, 1999, vol. 399, pp. 590593. https://doi.org/10.1038/21202

103. Parkinson, A.J., Davidson, M., Fitzgerald, M.A., Bulkow, L.R., and Parks, D.J., J. Infect. Dis., 1994, vol. 170 , pp. 461-464. https://doi.org/10.1093/infdis/170.2.461

104. Borgono, J.M., Mclean, A.A., and Vella, P.P., Proc. Soc. Biol. Med., 1978, vol. 157, pp. 148-154. https://doi.org/10.3181/00379727-157-40010

105. Kim, H.W., Lee, S., and Kim, K.-H., Medicine (Baltimore), 2016, vol. 95, p. e4854.

106. Lee, H., Cha, J.H., Nahm, M.H., Burton, R.L., and Kim, K.H., BMC Infect. Dis., 2013, vol. 13, p. e474. https://doi.org/10.1186/1471-2334-13-474

107. Kim, K.H., Korean J. Pediatr., 2005, vol. 48, pp. 506551.

108. Park, I.H., Geno, K.A., Yu, J., Oliver, M.B., Kim, K.H., and Nahm, M.H., Clin. Vaccine Immunol., 2015, 
vol. 22, pp. 313-318.

https://doi.org/10.1128/CVI.00647-14

109. Peeters, C.C.A.M., Evenberg, D., Hoogerhout, P., Kayhty, H., Saarinen, L., van Boeckel, C.A.A., van der Marel, G.A., van Boom, J.H., and Poolman, J.T., Infect. Immun., 1992, vol. 60, pp. 1826-1833. https://doi.org/10.1128/IAI.60.5.1826-1833.1992

110. Pozsgay, V., Chu, C., Pannell, L., Wolfe, J., Robbins, J.B., and Schneerson, R., Proc. Natl. Acad. Sci. U. S. A., 1999, vol. 96, pp. 5194-5197. https://doi.org/10.1073/pnas.96.9.5194

111. Thijssen, M.J.L., Bijkerk, M.H.G., Kamerling, J.P., and Vliegenthart, J.F.G., Carbohydr. Res., 1998, vol. 306 , pp. $111-125$. https://doi.org/10.1016/s0008-6215(97)10013-1

112. Thijssen, M.J.G., Halkes, K.M., Kamerling, J.P., and Vliegenthart, J.F.G., Bioorg. Med. Chem., 1994, vol. 2, pp. 1309-1317. https://doi.org/10.1016/s0968-0896(00)82081-7

113. Thijssen, M.J.G., van Rijswijk, M.N., Kamerling, J.P., and Vliegenthart, J.F.G., Carbohydr. Res., 1998, vol. 306, pp. 93-109. https://doi.org/10.1016/s0008-6215(97)00271-1

114. Parameswar, A.R., Park, I.H., Saksena, R., Kovac, P., Nahm, M.H., and Demchenko, A.V., ChemBioChem, 2009, vol. 10, pp. 2893-2899. https://doi.org/10.1002/cbic.200900587

115. Parameswar, A.R., Pornsuriyasak, P., Lubanowski, N.A., and Demchenko, A.V., Tetrahedron, 2007, vol. 63, pp. 10083-10091. https://doi.org/10.1016/j.tet

116. Sukhova, E.V., Yashunsky, D.V., Tsvetkov, Y.E., Nifantiev, N.E., and Kurbatova, E.A., J. Carbohydr. Chem., 2018, vol. 37, pp. 1-17. https://doi.org/10.1080/07328303.2017.1420797

117. Ménová, P., Sella, M., Sellrie, K., Pereira, C.L., and Seeberger, P.H., Chem.-Eur. J., 2018, vol. 24, pp. 4181-4187. https://doi.org/10.1002/chem.201705379

118. Ardanuy, C., de la Campa, A.G., García, E., Fenoll, A., Calatayud, L., Cercenado, E., Pérez-Trallero, E., Bouza, E., and Liñares, J., Emerg. Infect. Dis., 2014, vol. 20 , pp. $1848-1856$. https://doi.org/10.3201/eid2011.131215

119. Schumann, B., Hahm, H.S., Parameswarappa, S.G., Reppe, K., Wahlbrink, A., Govindan, S., Kaplonek, P., Pirofski, L.A., Witzenrath, M., Anish, C., Pereira, C.L., and Seeberger, P.H., Sci. Transl. Med., 2017, vol. 9, article eaaf5347.

https://doi.org/10.1126/scitranslmed.aaf5347

120. McNeely, T.B., Staub, J.M., Rusk, C.M., Blum, M.J., and Donnelly, J.J., Infect. Immun., 1998, vol. 66, pp. 3705-3710. https://doi.org/10.1128/iai.66.8.3705-3710.1998

121. Lee, C.-J., Karpas, A., Wang, T.R., Kosaka, T., and Koizumi, K., Microbiol. Immunol., 1996, vol. 40, pp. 857-865. https://doi.org/10.1111/j.1348-0421.1996.tb01151.X

122. Parameswarappa, S.G., Pereira, C.L., and Seeberger, P.H., Beilstein J. Org. Chem., 2020, vol. 16, pp. 1693-1699. https://doi.org/10.3762/bjoc.16.140
123. Seeberger, P.H., Claney, L., Govindan, P., and Govindan, S., Beilstein J. Org. Chem., 2017, vol. 13, pp. $164-173$.

https://doi.org/10.3762/bjoc.13.19

124. Mekada, E. and Uchida, T., J. Biol. Chem., 1985, vol. 260, pp. 12148-12153.

125. Kochetkov, NK., Nifant'ev, NE., and Backinowsky, L.V., Tetrahedron, 1987, vol. 43, pp. 3109-3121. https://doi.org/10.1016/S0040-4020(01)86852-6

126. Crane, D.T., Bolgiano, B., and Jones, C., Eur. J. Biochem., 1997, vol. 246, pp. 320-327. https://doi.org/10.1111/j.1432-1033.1997.00320.x

127. Tsvetkov, Y.E., Gening, M.L., Kurbatova, E.A., Akhmatova, N.K., and Nifantiev, N.E., Pure Appl. Chem., 2017, vol. 89, pp. 1403-1411. https://doi.org/10.1515/pac-2016-1123

128. Kurbatova, E.A., Akhmatova, N.K., Akhmatova, E.A., Egorova, N.B., Yastrebova, N.E., Sukhova, E.V., Yashunsky, D.V., Tsvetkov, Y.E., Gening, M.L., and Nifantiev, N.E., Front. Immunol., 2017, vol. 8, article 659. https://doi.org/10.3389/fimmu.2017.00659

129. Akhmatova, N.K., Kurbatova, E.A., Akhmatov, E.A., Egorova, N.B., Logunov, D.Y., Gening, M.L., and Nifantiev, N.E., Front. Immunol., 2016, vol. 7, article 248. https://doi.org/10.3389/fimmu.2016.00248

130. Safari, D., Dekker, H.A., Joosten, J.A., Michalik, D., de Souza, A.C., Adamo, R., Lahmann, M., Sundgren, A., Oscarson, S., and Kamerling, J.P., Infect. Immun., 2008, vol. 76, pp. 4615-4623. https://doi.org/10.1128/IAI.00472-08

131. Safari, D., Dekker, H.A., de Jong, B., Rijkers, G.T., Kamerling, J.P., and Snippe, H., Vaccine, 2011, vol. 29 , pp. $6498-6504$.

https://doi.org/10.1016/j.vaccine.2011.07.013

132. Safari, D., Marradi, M., Chiodo, F., Th, DekkerH.A., Shan, Y., Adamo, R., Oscarson, S., Rijkers, G.T., Lahmann, M., and Kamerling, J.P., Nanomedicine, 2012, vol. 7, pp. 651-662. https://doi.org/10.2217/nnm.11.151

133. de Velasco, E., Verheul, A.F., Veeneman, G.H., Gomes, L.J., van Boom, J.H., Verhoef, J., and Snippe, H., Vaccine, 1993, vol. 11, pp. 1429-1436. https://doi.org/10.1016/0264-410x(93)90172-t

134. Jansen, W.T.M., Verheul, A.F., Veeneman, G.H., van Boom, J.H., and Snippe, H., Vaccine, 2002, vol. 20, pp. 19-21. https://doi.org/10.1016/s0264-410x(01)00263-8

135. Vetro, M., Safari, D., Fallarini, S., Salsabila, K., Lahmann, M., Penades, S., Lay, L., Marradi, M., and Compostella, F., Nanomedicine, 2017, vol. 12, pp. 13-23. https://doi.org/10.2217/nnm-2016-0306

136. van Steijn, A.M., Kamerling, J.P., and Vliegenthart, J.F.G., Carbohydr. Res., 1991, vol. 211, pp. 261277. https://doi.org/10.1016/0008-6215(91)80096-6

137. van Steijn, A.M., Kamerling, J.P., and Vliegenthart, J.F.G., J. Carbohydr. Chem., 1992, vol. 11, pp. $665-689$. https://doi.org/10.1080/07328309208020085 
138. de Velasco, E., Verheul, A.F.M., van Steijn, A.M.P., Dekker, H.A.T., Feldman, R.G., Fernández, I.M., Kamerling, J.P., Vliegenthart, J.F.G., Verhoef, J., and Snippe, H., Infect. Immun., 1994, vol. 62, pp. 799808.

https://doi.org/10.1128/IAI.62.3.799-808.1994

139. Hyun, J.Y., Pai, J., and Shin, I., Acc. Chem. Res., 2017, vol. 50, pp. 1069-1078. https://doi.org/10.1021/acs.accounts.7b00043

140. Komarova, B.S., Orekhova, M.V., Tsvetkov, Y.E., Beau, R., Aimanianda, V., Latgé, J.-P., and Nifantiev, N.E., Chem.-Eur. J., 2015, vol. 21, pp. 1029-1035. https://doi.org/10.1002/chem.201404770

141. Krylov, V.B., Petruk, M.I., Grigoryev, I.V., Lebedin, Y.S., Glushko, N.I., Khaldeeva, E.V., Argunov, D.A., Khatuntseva, E.A., Toplishek, M.V., Komarova, B.S., Karelin, A.A., Yudina, O.N., Menshov, V.M., Yashunskii, D.V., Tsvetkov, Y.E., and Nifantiev, N.E., Russ. J. Bioorg. Chem., 2018, vol. 44, pp. 80-89. https://doi.org/10.1134/S1068162017060073

142. Argunov, D.A., Trostianetskaia, A.S., Krylov, V.B., Kurbatova, E.A., and Nifantiev, N.E., Eur. J. Org. Chem., 2019, vol. 2019, pp. 4226-4232. https://doi.org/10.1002/ejoc.201900389

143. Laverde, D., Romero-Saavedra, F., Argunov, D.A., Enotarpi, J., Krylov, V.B., Kalfopoulou, E., Martini, C., Torelli, R., van der Marel, G.A., Sanguinetti, M., Codée, J.D.C., Nifantiev, N.E., and Huebner, J., ACS Infect. Dis., 2020, vol. 6, pp. 1816-1826. https://doi.org/10.1021/acsinfecdis.0c00063

144. Matveev, A.L., Krylov, V.B., Emelyanova, L.A., Solovev, A.S., Khlusevich, Y.A., Baykov, I.K., Fontaine, T., Latgé, J.-P., Tikunova, N.V., and Nifantiev, N.E.,
PLoS One, 2018, vol. 13. e0193938.

https://doi.org/10.1371/journal.pone.0193938

145. Krylov, V.B. and Nifantiev, N.E., Curr. Top. Microbiol. Immunol. 2020 (in press). https://doi.org/10.1007/82_2019_187

146. Komarova, B.S., Tsvetkov, Y.E., and Nifantiev, N.E., Chem. Rec., 2016, vol. 16, pp. 488-506. https://doi.org/10.1002/tcr.201500245

147. Komarova, B.S., Orekhova, M.V., Tsvetkov, Y.E., and Nifantiev, N.E., Carbohydr. Res., 2014, vol. 384, pp. $70-86$. https://doi.org/10.1016/j.carres.2013.11.016

148. Krylov, V.B., Argunov, D.A., Vinnitskiy, D.Z., Verkhnyatskaya, S.A., Gerbst, A.G., Ustyuzhanina, N.E., Dmitrenok, A.S., Huebner, J., Holst, O., Siebert, H.-C., and Nifantiev, N.E., Chem.-Eur. J., 2014, vol. 20, pp. 16516-16522.

149. Tokatly, A.I., Vinnitskiy, D.Z., Ustyuzhanina, N.E., and Nifantiev, N.E., Russ. J. Bioorg. Chem., 2021, vol. 47, pp. 52-68.

150. Pardo-Vargas, A., Delbianco, M., and Seeberger, P.H., Curr. Opin. Chem. Biol., 2018, vol. 46, pp. 48-55. https://doi.org/10.1016/j.cbpa.2018.04.007

151. Louçano, J., Peter, B., Marchesi, A., del Bino, L., Adamo, R., Flitsch, S., and Salwiczek, M., RSC Adv., 2020, vol. 10, pp. 23668-23674. https://doi.org/10.1039/d0ra01803a

152. Cavallari, M., Stallforth, P., Kalinichenko, A., Rathwell, D.C.K., Gronewold, T.M.A., Adibekian, A., Mori, L., Landmann, R., Seeberger, P.H., and De Libero, G., Nat. Chem. Biol., 2014, vol. 10, pp. 950956.

https://doi.org/10.1038/nchembio.1650 